\title{
Intestinal Batf3-dependent dendritic cells are required for optimal antiviral T-cell responses in adult and neonatal mice
}

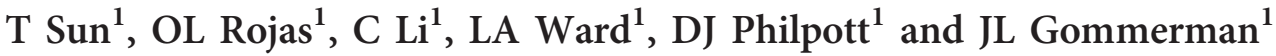

\begin{abstract}
Although we know a great deal about which types of dendritic cells (DCs) promote T-cell priming in the periphery, less is known about which DC subset(s) provoke antiviral responses within the gut. Here we report that conventional Zbtb46dependent DCs were critically required for antiviral $\mathrm{CD}^{+} \mathrm{T}$-cell responses against rotavirus (RV), the major cause of childhood gastroenteritis worldwide. Furthermore, we found that in adult mice, Batf3-dependent DCs were required for generating optimal RV-specific CD8 ${ }^{+} \mathrm{T}$-cell responses. However, in contrast to mice that lack Zbtb46-dependent DCs, a significant amount of interferon gamma-producing RV-specific CD8 ${ }^{+}$Tcells were still detected in the small intestine of RV-infected adult Batf3 ${ }^{-/-}$mice, suggesting the existence of compensatory cross-presentation mechanisms in the absence of Batf3-dependent DCs. In contrast to adult mice, we found that Batf3-dependent DCs were absolutely required for generating RV-specific $\mathrm{CD}^{+} \mathrm{T}$-cell responses in neonates. Loss of Batf3-dependent DCs also resulted in a skewed polyclonal $\mathrm{CD} 4^{+} \mathrm{T}$-cell response in both adult and neonatal mice upon $\mathrm{RV}$ infection, although local and systemic RV-specific immunoglobulin A production kinetics and titers were unimpaired. Our results provide insights that inform early-life vaccination strategies against RV infection.
\end{abstract}

\section{INTRODUCTION}

Dendritic cells (DCs) are the major antigen-presenting cells (APCs) responsible for first-line defense against pathogens and are principal coordinators of the innate and adaptive immune response to pathogens. DCs arise from common myeloid progenitors in the bone marrow (BM). After progressing through developmental stages as macrophage DC precursors and common DC progenitors, pre-DCs exit the BM and seed lymphoid and non-lymphoid tissues. ${ }^{1}$ Zbtb46 (BTBD4), a transcription factor belonging to the BTB-ZF (Broad complex, Tramtrack, Bric-à-brac, and Zinc finger) family, is induced from the pre-DC stage, and its expression is maintained in fully differentiated conventional DCs (cDCs) but not plasmacytoid DCs (pDCs) or macrophages. ${ }^{2} \mathrm{cDCs}$ can be further separated based on the surface expression of $\mathrm{CD} 8 \alpha$ and CD11b in lymphoid tissues or CD103 and CD11b in non-lymphoid tissues. Within peripheral lymphoid and non-lymphoid tissues, these DC subsets exert distinct functions: the $\mathrm{CD} 8 \alpha^{+} \mathrm{CD} 11 \mathrm{~b}^{-}$ or $\mathrm{CD}_{103}{ }^{+} \mathrm{CD} 11 \mathrm{~b}^{-} \mathrm{DC}$ subset is specialized in cross- presenting intracellular pathogens or tumor antigens to $\mathrm{CD}^{+} \mathrm{T}$ cells and producing interleukin (IL)-12, ${ }^{3,4}$ whereas the $\mathrm{CD} 8 \alpha^{-} \mathrm{CD} 11 \mathrm{~b}^{+}$or $\mathrm{CD} 103^{+} \mathrm{CD} 11 \mathrm{~b}^{+}$DC subsets, which produce IL-23 and IL-6, are thought to be specialized in the induction of $\mathrm{CD}^{+}{ }^{+}$T-cell responses. ${ }^{5,6}$ In the gut-associated lymphoid tissues, emerging data have shown that specific DC subsets are required for controlling certain types of pathogenspecific responses, particularly in the large bowel (e.g., Citrobacter rodentium infection ${ }^{7}$ ). However, very little is known about which DC subset(s) mediate clearance of small intestinal-tropic viral infections.

Lineage specification of $\mathrm{CD} 8 \alpha^{+} \mathrm{CD} 11 \mathrm{~b}^{-}$and $\mathrm{CD} 103^{+}$ $\mathrm{CD}_{11 \mathrm{~b}^{-}} \mathrm{cDCs}$ requires basic leucine zipper transcription factor ATF-like 3 (Batf3) and interferon (IFN) regulatory factor $8 .^{8}$ Mice with Batf3 deficiency $\left(\mathrm{Batf}^{-1-}\right)$ exhibit a selective loss of $\mathrm{CD} 8 \alpha^{+} \mathrm{CD} 11 \mathrm{~b}^{-}$cDCs within lymphoid tissues and $\mathrm{CD} 103^{+} \mathrm{CD}_{11 \mathrm{~b}}{ }^{-}$cDCs within non-lymphoid tissues, ${ }^{9}$ without apparent abnormalities in other hematopoietic cell types. ${ }^{3}$ It has been reported that Batf3-dependent DCs are involved in

${ }^{1}$ Department of Immunology, University of Toronto, Toronto, Ontario, Canada. Correspondence: JL Gommerman (jen.gommerman@utoronto.ca) 
mediating adaptive immune responses against various pathogens such as West Nile virus (WNV) ${ }^{3}$ and cytomegalovirus ${ }^{10,11}$ via antiviral $\mathrm{CD}^{+}{ }^{+} \mathrm{T}$-cell responses, as well as Toxoplasma gondii $^{4}$ and Leishmania major ${ }^{12}$ through DC-secreted IL-12. In the respiratory mucosa, Waithman et al. ${ }^{13}$ have shown that Batf3-dependent DCs mediate $\mathrm{CD}^{+}{ }^{+} \mathrm{T}$-cell responses to influenza virus. However, it is not known whether Batf3dependent DCs contribute to the clearance of virus within the intestines, especially the small bowel. Furthermore, it has been reported that during respiratory syncytial virus infection, neonatal $\mathrm{CD}_{103}{ }^{+}$DCs in the mediastinal lymph nodes provoke a fundamentally different $\mathrm{CD} 8{ }^{+} \mathrm{T}$-cell response profile than $\mathrm{CD}_{103}{ }^{+}$DCs from adult mice, ${ }^{14}$ suggesting that mucosal DCs exhibit age-dependent properties. Investigating how intestinal DCs differ between adults and neonates in initiating adaptive antiviral responses may provide us with better strategies for vaccine design.

Rotavirus (RV) is a double-stranded RNA virus belonging to the Reoviridae family and is a leading cause of severe diarrhea in children aged $<5$ years. Although RV infections in adults are typically asymptomatic or mild, immunosuppressed organ transplantation recipients are susceptible to RV infection, and these patients can develop significant gastroenteritis. ${ }^{15}$ Similar to children, neonatal/suckling mice also develop diarrhea after oral infection, while adult mice remain asymptomatic upon infection, although viral shedding can still be detected in the feces (an indicator of viral presence). RV infection of mice is a well-defined model system for studying viral infection in the small intestine as RV predominantly infects and replicates within mature epithelial cells on the tip of the small intestinal villi. ${ }^{16}$ In adult mice, $\mathrm{CD} 8{ }^{+} \mathrm{T}$ cells have a role in the timely resolution of primary RV infection, while RV-specific immunoglobulin A (IgA) is important for viral clearance after primary infection and for preventing reinfections. ${ }^{17,18}$

In adult RV-infected mice, it has been reported that pDCs have an important role in promoting the differentiation of activated B cells into plasma cells via type I IFN secretion. ${ }^{19}$ In terms of the role of $\mathrm{cDC}, \mathrm{CD} 11 \mathrm{c}^{+}$cells in the subepithelial dome of Peyer's patches co-localize with RV. ${ }^{20}$ These CD11c ${ }^{+}$ cells also upregulate co-stimulatory molecules (CD80, CD86, and $\mathrm{CD} 40$ ) and increase the expression of proinflammatory cytokines (IL-12/23p40 and tumor necrosis factor $\alpha$ ) at early time points postinfection. ${ }^{21}$ However, it is not clear what specific DC subtype primes RV-specific $\mathrm{T}$ cells in adults or neonates. Furthermore, while the innate response to RV has been studied in neonatal mice, ${ }^{22,23}$ a comprehensive study of the neonatal anti-RV adaptive immune response contrasted with adult anti-RV responses has not been performed.

In the current study, we generated Zbtb46-diphtheria toxin receptor (DTR) $\rightarrow$ wild-type (WT) BM chimeric mice and treated reconstituted chimeric mice with diphtheria toxin (DTx) to deplete cDCs without altering macrophages or pDCs. ${ }^{2,24}$ DTx-treated Zbtb46-DTR $\rightarrow$ WT chimeric mice were able to clear RV, albeit with prolonged viral shedding compared with phosphate-buffered saline (PBS)-treated control chimeras. However, in the absence of cDCs, the antigen-specific
$\mathrm{CD}^{+}{ }^{+} \mathrm{T}$-cell response in the small intestinal lamina propria (SILP) was largely lacking at 7 days postinfection (d.p.i.). Likewise, RV-infected Batf3 $3^{-1-}$ mice exhibited prolonged viral shedding and decreased $\mathrm{RV}$-specific $\mathrm{CD}^{+}$T-cell responses at 7 d.p.i. Unlike the DTx-treated Zbtb46-DTR $\rightarrow$ WT chimeric mice, however, residual antigen-specific CD8 ${ }^{+}$ $\mathrm{T}$-cell responses were readily detected in Batf $3^{-1-}$ mice, suggesting that other APCs can compensate for the absence of Batf3-dependent cDCs to mediate cross-presentation of RV antigen to $\mathrm{CD}^{+}{ }^{+} \mathrm{T}$ cells. Interestingly, compared with adult mice, neonates exhibited a more stringent dependency on Batf3-dependent cDCs for the induction of anti-RV CD8 ${ }^{+}$ $\mathrm{T}$-cell responses, suggesting differential DC plasticity in adults compared with neonates. Local and systemic anti-RV IgA responses were largely intact in both DTx-treated Zbtb46$\mathrm{DTR} \rightarrow \mathrm{WT}$ chimeras and $B a t f 3^{-1-}$ mice, suggesting a dispensable role of $\mathrm{cDCs}$ in generating antiviral IgA responses. These results provide important insights into the $\mathrm{CD} 8{ }^{+} \mathrm{T}$-cell response to RV in the small intestine and may shed light on strategies for vaccine design.

\section{RESULTS}

\section{Depletion of Zbtb46-dependent cDCs is not affected by RV infection}

Zbtb46 is a transcription factor expressed by cDCs (and preDCs) as well as by definitive erythroid precursors and endothelial cells but not in macrophages or pDCs. ${ }^{2,24}$ The non-hematopoietic expression of Zbtb46 makes Zbtb46-DTR mice vulnerable to DTx treatment owing to DTx-mediated toxicity. ${ }^{24}$ We therefore reconstituted lethally irradiated WT mice with Zbtb46-DTR BM in order to avoid targeting DTxsensitive non-hematopoietic cells. Eight to 10 weeks after BM transplantation, we injected chimeras via the intraperitoneal route with DTx 1 day prior and throughout the period of RV infection. Using flow cytometry, we found that SILP cDCs were markedly reduced in DTx-treated Zbtb46-DTR $\rightarrow$ WT chimeric mice compared with PBS-treated chimeric mice and that depletion efficacy was not affected by RV infection (Figure 1a,b; gating strategies are described in Supplementary Figure S1a online). Other APCs such as macrophages and B cells were not altered after DTx treatment or upon RV challenge (Figure 1c,d). In terms of $\mathrm{CDC}$ subsets in the SILP, $\mathrm{CD} 103^{+} \mathrm{CD} 11 \mathrm{~b}^{-}$DCs and the majority of $\mathrm{CD}_{103}{ }^{+} \mathrm{CD}_{11 \mathrm{~b}^{+}}$DCs were depleted by DTx treatment (Figure 1e-g). Similar results were observed when absolute number of cells was tabulated (see Supplementary Figure S1b-d). A concomitant increase in the frequency, but not absolute numbers, of $\mathrm{CD} 103^{-} \mathrm{CD} 11 \mathrm{~b}^{+}$cells was observed with DTx treatment of Zbtb46-DTR $\rightarrow$ WT chimeric mice (Figure $1 \mathrm{~h}$ and see Supplementary Figure S1e).

Mesenteric lymph nodes (MLNs) are the draining lymph nodes of the intestines, and DCs that have captured antigen can transport antigen to the MLN via lymphatics in order to crossprime $\mathrm{CD} 8{ }^{+} \mathrm{T}$ cells. ${ }^{25}$ We therefore also evaluated the DC populations in the MLNs from DTx- vs. PBS-treated Zbtb46DTR $\rightarrow$ WT chimeric mice. DTx treatment of Zbtb46-DTR $\rightarrow$ WT chimeric mice was found to deplete both migratory and 
a

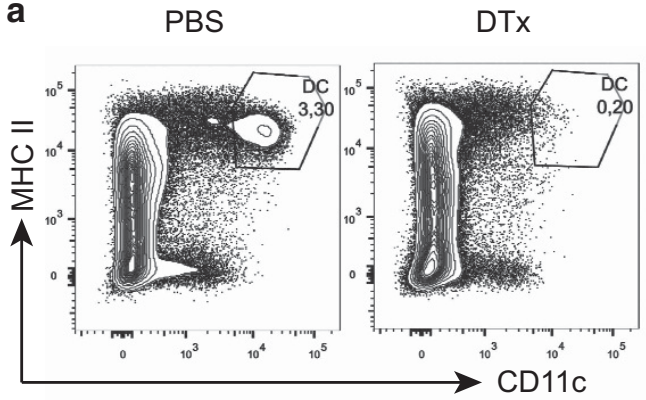

e

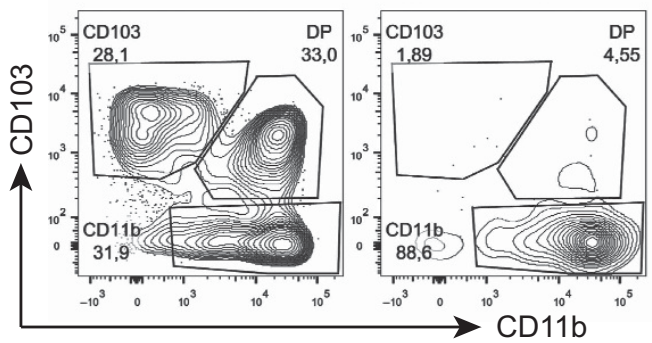

b

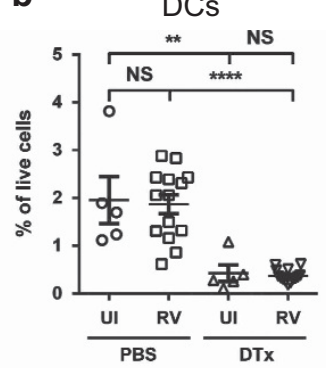

f

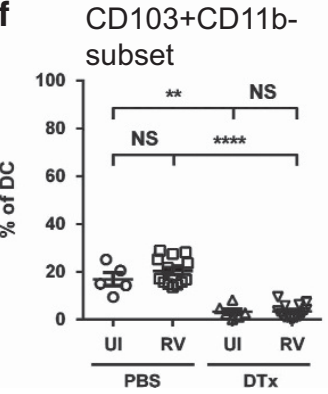

C

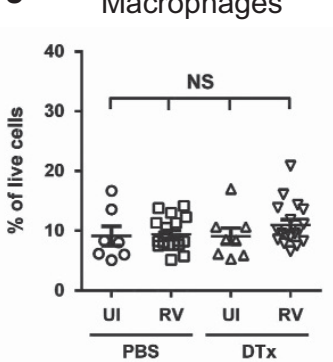

g

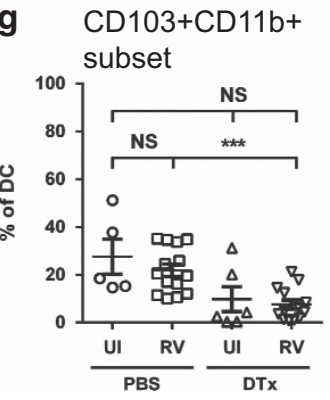

d

B cells

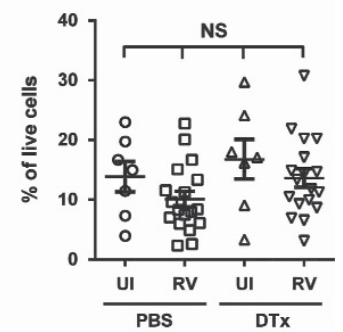

h
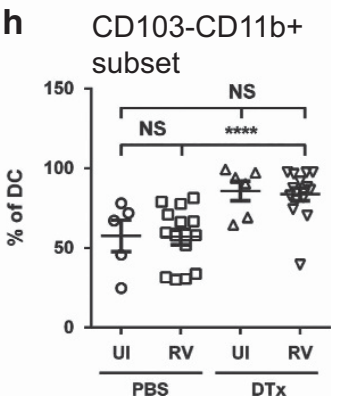

Figure 1 Conventional dendritic cell (DC) populations in diphtheria toxin (DTx)-treated Zbtb46-diphtheria toxin receptor (DTR) $\rightarrow$ wild-type (WT) chimeric mice. (a) Representative flow cytometric plots of $\mathrm{CD}_{11 \mathrm{c}}{ }^{+} \mathrm{MHC} \mathrm{II}^{+}$small intestinal lamina propria (SILP) DCs (detailed gating strategies are shown in Supplementary Figure S1) from mice treated with phosphate-buffered saline (PBS) or DTx at 7 days postinfection (d.p.i.). (b) Percentage of SILP DCs as a frequency of mononuclear cells from mice treated with PBS or DTx at 7 d.p.i. (c, d) Percentage of SILP macrophages and B cells as a frequency of mononuclear cells (detailed gating strategies are shown in Supplementary Figure S1) at 7 d.p.i. (e) Representative flow cytometric plots showing the gating strategy of SILP DC subsets (pregated as in Figure 1a) from mice treated with PBS or DTx. (f-h) Percentage of SILP DC subsets as a frequency of DCs at 7 d.p.i. DP, $C D 103^{+} \mathrm{CD} 11 \mathrm{~b}^{+} ; \mathrm{RV}$, rotavirus infected; UI, uninfected. Results were pooled from four independent experiments. Each data point represents a single biological replicate (one mouse). Data are presented as mean \pm s.e.m. Mann-Whitney test. ${ }^{* \star} P<0.01,{ }^{* \star \star} P<0.001$, ${ }^{* * * \star} P<0.0001, \mathrm{NS}=$ not significant. Please see Supplementary Figure $\mathbf{S} 1$ for further related information.

resident DCs (mDCs and $\mathrm{rDCs}$ ) and their subsets (defined in Supplementary Figure S1f,g-m). In summary, we confirmed that DTx treatment efficiently depletes $\mathrm{CDC}$ in Zbtb46-DTR $\rightarrow$ WT chimeric mice.

\section{Zbtb46-dependent CDCs are required for anti-RV CD8 T-cell responses}

To determine whether cDCs are required for anti-RV CD8 ${ }^{+}$ T-cell responses, DTx-treated Zbtb46-DTR $\rightarrow$ WT chimeric mice and PBS-treated controls were orally infected with RV. Although the frequency of SILP CD8 ${ }^{+} \mathrm{T}$ cells at steady state was not affected by DTx treatment (Figure 2a), following RV challenge, cDC-deficient mice exhibited severely impaired $\mathrm{CD} 8{ }^{+}$T-cell proliferation corresponding with a reduction in $\mathrm{CD} 8^{+} \mathrm{T}$-cell frequency after RV challenge (Figure 2a,b). Antigen-specific CD8 ${ }^{+} \mathrm{T}$-cell responses were subsequently evaluated. Specifically, the $\mathrm{CD}^{+}{ }^{+} \mathrm{T}$-cell response to $\mathrm{VP}_{357-366}$, one of the immunodominant $\mathrm{RV}$ epitopes recognized by $\mathrm{H}-2^{\mathrm{b}}$-restricted $\mathrm{CD} 8^{+}$ $\mathrm{T}$ cells, ${ }^{26}$ was examined via tetramer staining along with $\mathrm{VP}_{357-366}$ peptide restimulation to measure IFN $\gamma$ production (see Supplementary Figure S2a,b, respectively). At 7 d.p.i., the frequency of $\mathrm{VP}_{357-366}$-specific CD8 ${ }^{+} \mathrm{T}$ cells in the SILP was significantly reduced in the absence of cDCs (Figure 2c). In parallel, after in vitro restimulation with $\mathrm{VP}_{357-366}$ peptide, the percentage of $\mathrm{CD} 8{ }^{+}$T cells capable of producing IFN $\gamma$ was significantly reduced in the absence of cDCs (Figure 2d). Reduced absolute numbers of
$\mathrm{CD}^{+}{ }^{+} \mathrm{T}$ cells, $\mathrm{VP}_{357-366^{-}}$specific $\mathrm{CD} 8^{+} \mathrm{T}$ cells, and $\mathrm{IFN} \gamma^{+}$ $\mathrm{CD}^{+}{ }^{+} \mathrm{T}$ cells were also observed in RV-infected Zbtb46DTR $\rightarrow$ WT chimeric mice (see Supplementary Figure S2c-f). A similar reduction of antigen-specific $\mathrm{CD} 8{ }^{+} \mathrm{T}$ cells was also observed in the intraepithelial lymphocyte (IEL) compartment, although the frequency of $\mathrm{CD}^{+} \mathrm{T}$ cells within the IEL compartment was unaffected by DTx treatment (Figure 2e).

Finally, in the absence of cDCs, Zbtb46-DTR $\rightarrow$ WT chimeric mice exhibited a continuous shedding of $\mathrm{RV}$ into the gut lumen (measured in the fecal pellet) until 7 d.p.i. compared with control chimeras (Figure 2f), suggesting a requirement for $\mathrm{CDC}$ and the downstream antiviral $\mathrm{CD} 8^{+} \mathrm{T}$-cell response in mediating optimal RV clearance. However, this prolonged viral shedding was only transient, implying that compensatory mechanisms beyond the $\mathrm{RV}$-specific $\mathrm{CD} 8{ }^{+} \mathrm{T}$-cell response exist to mediate RV clearance. Taken together, these results suggest that $\mathrm{CDCs}$ are required for $\mathrm{CD} 8{ }^{+} \mathrm{T}$-cell priming to $\mathrm{RV}$.

\section{Adult and neonatal Batf3 ${ }^{-1-}$ mice exhibit similar deficiencies in $\mathrm{CD} 103^{+} \mathrm{CD}^{-11 b}{ }^{-}$DCs both at steady state and during $\mathbf{R V}$ infection}

As $\mathrm{CD}_{103}{ }^{+} \mathrm{CD}_{11 \mathrm{~b}^{-}} \mathrm{cDCs}$ specialize in the cross-presentation of viral and tumor antigens to $\mathrm{CD} 8^{+} \mathrm{T}$ cells, we speculated that these $\mathrm{cDCs}$ would be required for priming $\mathrm{CD} 8^{+} \mathrm{T}$ cells upon $\mathrm{RV}$ challenge. Recent studies have shown that the transcription factor Batf3 is required for the development of both lymphoid 
a

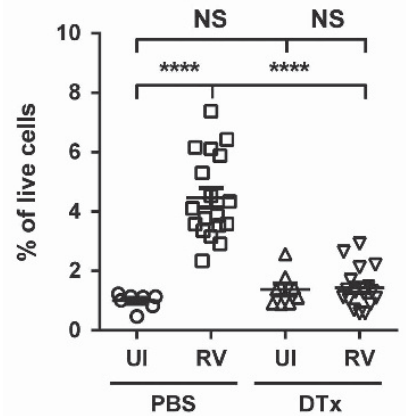

b

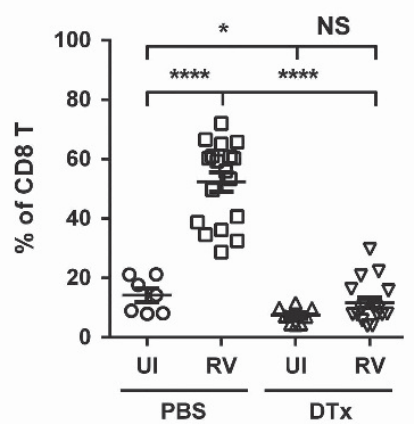

C

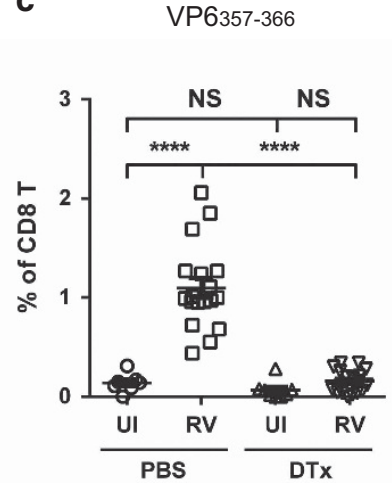

d

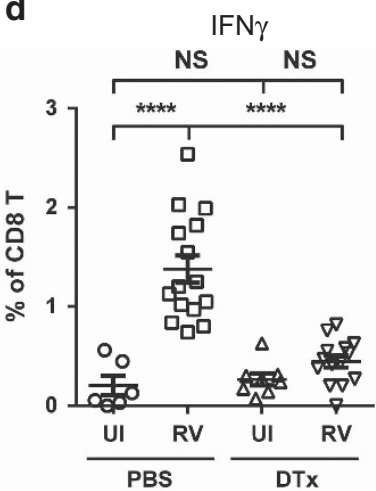

e

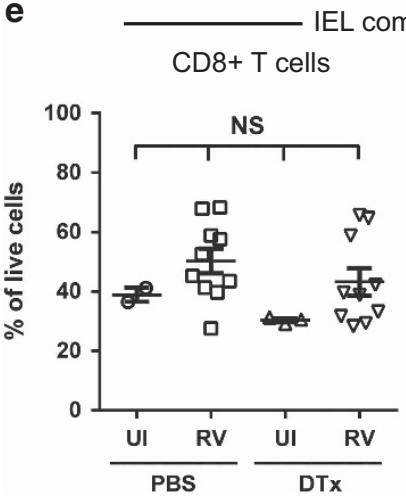

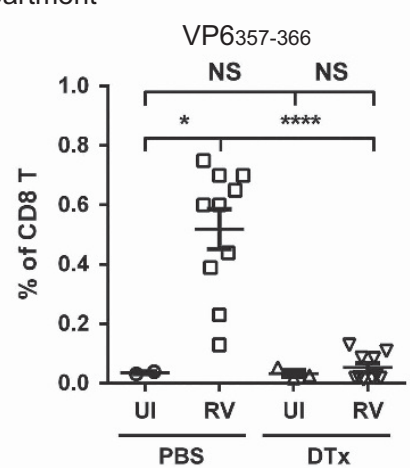

$\mathbf{f}$

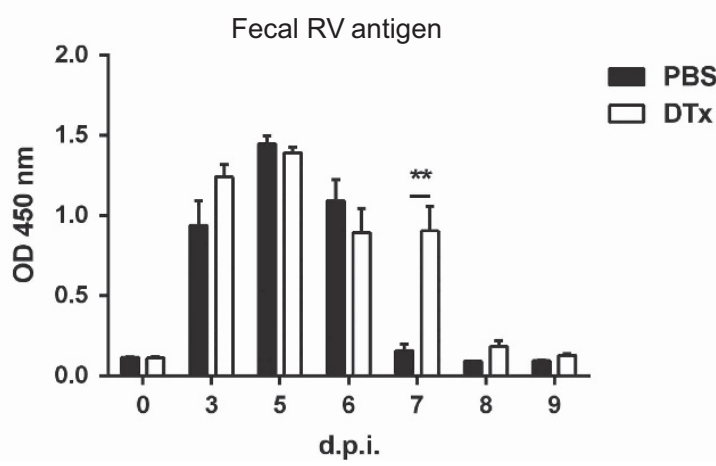

Figure 2 Zbtb46-dependent conventional dendritic cells (DCs) are required to prime rotavirus (RV)-specific CD8 ${ }^{+} \mathrm{T}_{\text {cells. }}$ (a) Percentage of CD8 ${ }^{+} \mathrm{T}$ cells as a frequency of small intestinal lamina propria (SILP) mononuclear cells at 7 days postinfection (d.p.i.). (b) Percentage of Ki- $67^{+}$cells as a frequency of SILP CD8 ${ }^{+}$T cells at 7 d.p.i. (c) Percentage of VP $6_{357-366}^{+}$cells as a frequency of SILP CD8 ${ }^{+}$T cells at 7 d.p.i. (d) Percentage of IFN $\gamma^{+}$cells as a frequency of SILP CD8 ${ }^{+} \mathrm{T}$ cells after in vitro restimulation with VP6 ${ }_{357-366}$ peptide at 7 d.p.i. (e) Percentage of intraepithelial $\mathrm{CD}^{+} \mathrm{T}^{+}$cells as a frequency of mononuclear cells and the percentage of intraepithelial VP $6_{357-366}^{+}$cells as a frequency of CD8 ${ }^{+} \mathrm{T}$ cells at 7 d.p.i. (f) Level of RV antigen in the feces measured by enzyme-linked immunosorbent assay. DTx, diphtheria toxin; UI, uninfected. Results were pooled from three to four independent experiments. Each data point represents a single biological replicate (one mouse). Data are presented as mean \pm s.e.m. (a), Student's $t$-test; (b-f), Mann-Whitney test. ${ }^{\star} P<0.05,{ }^{\star \star} P<0.01,{ }^{\star \star \star \star} P<0.0001, \mathrm{NS}=$ not significant. Please see Supplementary Figure $\mathbf{S} 2$ for further related information.

$\mathrm{CD} 8 \alpha^{+} \mathrm{CD}_{11 \mathrm{~b}^{-}}$and non-lymphoid $\mathrm{CD} 103^{+} \mathrm{CD}_{11 \mathrm{~b}^{-} \mathrm{DCs} \text { in }}$ mice. ${ }^{3,9}$ At steady state, we confirmed that $\mathrm{Batf}^{-1-}$ mice displayed a selective loss of $\mathrm{CD}_{103}{ }^{+} \mathrm{CD} 11 \mathrm{~b}^{-} \mathrm{cDCs}$. This loss in $\mathrm{CD}_{103}{ }^{+} \mathrm{CD}_{11 \mathrm{~b}^{-}} \mathrm{cDCs}$ was accompanied by an increased frequency of $\mathrm{CD}_{103}{ }^{-} \mathrm{CD} 11 \mathrm{~b}^{+}$cells in the SILP, compared with Batf $3^{+/-}$littermates, whereas $\mathrm{CD}_{103}{ }^{+} \mathrm{CD} 11 \mathrm{~b}^{+} \mathrm{cDCs}$ remained unchanged (Figure 3a). Upon RV infection, while no changes were observed in the $\mathrm{CDC}$ frequency (Figure $3 \mathbf{b}$ ) nor in the $\mathrm{CD}_{103}{ }^{+} \mathrm{CD}_{11 \mathrm{~b}^{-}} \mathrm{cDC}$ population (Figure 3a), both Batf $3^{-1-}$ mice and Batf $3^{+/-}$littermates exhibited slightly decreased frequencies of $\mathrm{CD} 103^{+} \mathrm{CD}_{11 b^{+}} \mathrm{cDCs}$ and increased frequencies of $\mathrm{CD}_{103}{ }^{-} \mathrm{CD} 11 \mathrm{~b}^{+} \mathrm{cDCs}$ compared with uninfected (UI) genotype matched controls (Figure 3a). Similar results were observed when absolute number of cells was tabulated (see Supplementary Figure S3a-d). In the MLN, we found that absolute numbers of $\mathrm{CD}_{103}{ }^{+} \mathrm{CD}_{11 b^{-}}$ mDCs and $\mathrm{CD} 8 \alpha^{+} \mathrm{CD} 11 \mathrm{~b}^{-}$rDCs were significantly decreased, whereas the absolute number of $\mathrm{CD}_{103}{ }^{+} \mathrm{CD}_{11 \mathrm{~b}}{ }^{+}$and $\mathrm{CD}_{103}{ }^{-} \mathrm{CD}_{11 \mathrm{~b}^{+}} \mathrm{mDCs}$ was significantly elevated in Batf $3^{-1-}$ mice (see Supplementary Figure S3e-k). In terms of other APCs, we observed no changes in the macrophage population (Figure 3c) and a trend toward a reduction in $\mathrm{B}$ cells following RV infection of Batf $3^{-1-}$ mice (Figure 3d).
As neonatal mice are highly susceptible to oral RV infection and the specific DC subset(s) required to initiate neonatal adaptive responses remains to be determined, we also examined DC populations in Batf $3^{-1-}$ neonates. Accordingly, day 5-6 postnatal Batf3 ${ }^{+/-}$and $\mathrm{Batf}^{-1-}$ littermates were examined and are referred to hereafter as neonatal mice. At steady state, compared with littermate controls, neonatal Batf $3^{-1-}$ mice displayed a profound loss of $\mathrm{CD} 103^{+} \mathrm{CD} 11 \mathrm{~b}^{-} \mathrm{DCs}$, as well as a modest reduction in $\mathrm{CD}_{103}{ }^{+} \mathrm{CD}_{11 \mathrm{~b}}{ }^{+}$DCs (Figure 3e). Similar to adult $\mathrm{Batf}^{-1-}$ mice, RV infection did not alter the SILP $\mathrm{cDC}$ frequency in neonatal mice (Figure 3f). Other APCs such as macrophages and $\mathrm{B}$ cells were maintained at similar frequencies at steady state as well as upon RV infection in Batf $3^{-1-}$ neonates (Figure 3g,h, respectively). Together, these results suggest that adult and neonatal Batf $3^{-1-}$ mice share similarities in SILP APC profiles before and after RV infection.

\section{Adult and neonatal mice have distinct $\mathrm{DC}$ requirements for mounting RV-specific CD8 ${ }^{+}$T-cell responses}

We next examined the anti-RV CD8 ${ }^{+} \mathrm{T}$-cell response in the SILP, the effector site for primed CD8 ${ }^{+} \mathrm{T}$ cells. Both adult and neonatal Batf $3^{-1-}$ mice exhibited a decreased frequency in 
a

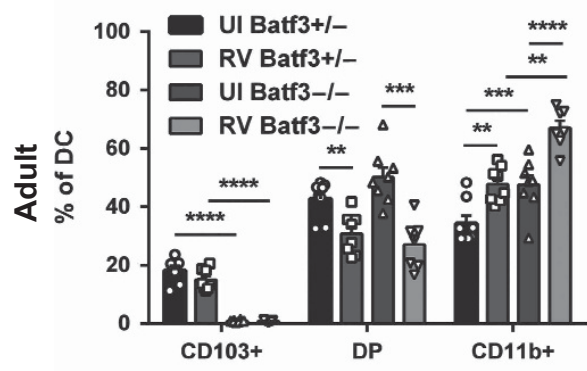

e

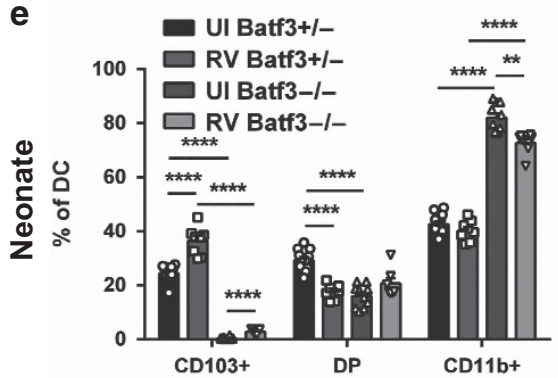

b

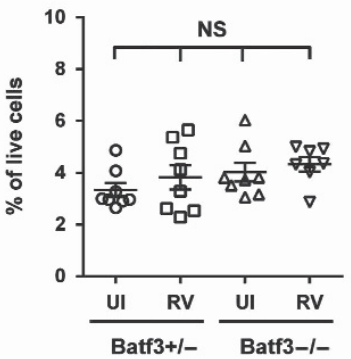

f

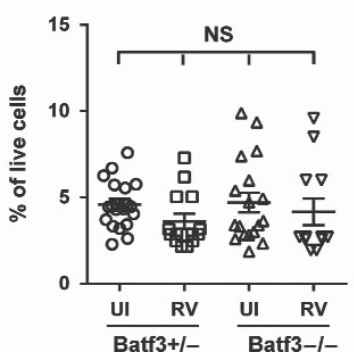

c Macrophages

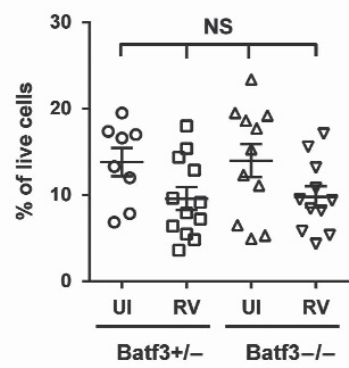

g

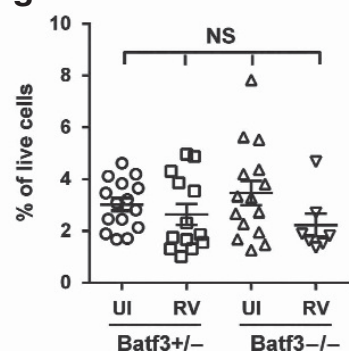

d B cells

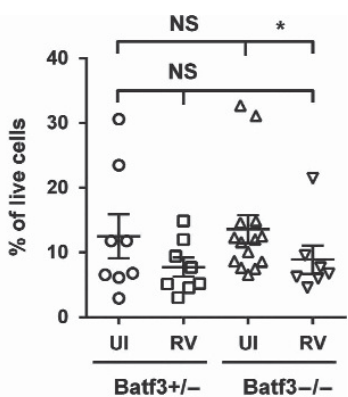

h

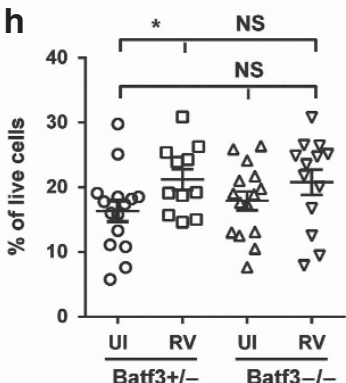

Figure 3 Antigen-presenting cells in the small intestinal lamina propria (SILP) of adult and neonatal Batf ${ }^{-1-}$ mice at steady state and upon rotavirus (RV) infection. (a) Percentage of DC subsets as a frequency of DCs in adult mice at 7 days postinfection (d.p.i.). (b) Percentage of DCs as a frequency of mononuclear cells in adult mice at 7 d.p.i. (c) Percentage of macrophages as a frequency of mononuclear cells in adult mice at 7 d.p.i. (d) Percentage of $B$ cells as a frequency of mononuclear cells in adult mice at 7 d.p.i. (e) Percentage of DC subsets as a frequency of DCs in neonatal mice at 7 d.p.i. (f) Percentage of DCs as a frequency of mononuclear cells in neonatal mice at 7 d.p.i. (g) Percentage of macrophages as a frequency of mononuclear cells in neonatal mice at 7 d.p.i. (h) Percentage of B cells as a frequency of mononuclear cells in neonatal mice at 7 d.p.i. UI, uninfected. DP, $\mathrm{CD}_{103}{ }^{+} \mathrm{CD} 11 \mathrm{~b}^{+} \mathrm{DC}$. Results were pooled from three to four independent experiments. Each data point represents a single biological replicate (one mouse). Data are presented as mean \pm s.e.m. (a-c) and (e-h), Student's $t$-test; (d), Mann-Whitney test. ${ }^{*} P<0.05,{ }^{* *} P<0.01,{ }^{* * *} P<0.001$, ${ }^{\star * \star \star} P<0.0001, \mathrm{NS}=$ not significant. Please see Supplementary Figure S3 for further related information.

total $\mathrm{CD}^{+} \mathrm{T}$ cells compared with $\mathrm{Batf}^{+/-}$littermates (Figure 4a,b, respectively), which was likely caused by poor proliferation as indicated by a reduced frequency of Ki$67^{+} \mathrm{CD} 8^{+} \mathrm{T}$ cells (Figure $4 \mathbf{c}, \mathbf{d}$, respectively). Moreover, $\mathrm{CD}^{+}$T-cell activation (indicated by CD44 staining) was reduced in RV-infected adult and neonatal Batf3 $3^{-1-}$ mice compared with $\mathrm{Batf}^{+/-}$littermates (Figure 4e,f, respectively). Interestingly, although the frequency of $\mathrm{VP}_{357-366^{-}}$specific $\mathrm{CD}^{+} \mathrm{T}$ cells (Figure 4g) and $\mathrm{VP}_{357-366}$ peptide-induced IFN $\gamma$-producing $\mathrm{CD}^{+} \mathrm{T}$ cells were decreased in adult Batf $3^{-1-}$ mice, the $\mathrm{CD} 8^{+} \mathrm{T}$-cell response to $\mathrm{RV}$ was not eliminated (Figure $\mathbf{4 h}$ ). Similar results in adult Batf3 mice were observed when absolute number of cells was tabulated (see Supplementary Figure S4). In concordance with these defects in $\mathrm{CD} 8^{+}$T-cell responses, adult Batf3 $3^{-1-}$ mice were also found to shed significantly higher levels of RV compared with Batf $3^{+/-}$littermate controls, although RV clearance was restored by 8 d.p.i. (Figure $4 \mathbf{i}$ ).

In contrast to what we observed in adult $\mathrm{Batf}^{-1-}$ mice, neonatal $\mathrm{Batf} 3^{-1-}$ mice were incapable of mounting antigenspecific $\mathrm{CD}^{+}{ }^{+} \mathrm{T}$-cell responses in the SILP (Figure 4j,k). Nevertheless, neonatal Batf $3^{-1-}$ mice cleared RV with similar kinetics compared to Batf3 $3^{+/-}$littermates (Figure 4l), suggesting that a $\mathrm{RV}$-specific $\mathrm{CD} 8^{+} \mathrm{T}$-cell response is not absolutely required for RV clearance in neonates. Together, these results suggest that Batf3-dependent DCs are required for optimal antiviral $\mathrm{CD} 8{ }^{+} \mathrm{T}$-cell responses in both adult and neonatal mice, with a more stringent requirement for Batf3-dependent DCs in neonatal mice.

\section{Polyclonal antiviral Th1 responses in neonatal mice are Batf3 dependent}

Although anti-RV CD4 ${ }^{+}$T-cell responses are dispensable for $\mathrm{RV}$ clearance, they do have a role in providing help for the antiRV IgA response. ${ }^{27}$ To evaluate the $\mathrm{CD} 4{ }^{+} \mathrm{T}$-cell profile, we used the mitogen phorbol 12-myristate 13-acetate and the calcium ionophore ionomycin for in vitro restimulation of SILP CD4 ${ }^{+} \mathrm{T}$ cells following RV infection. Although the frequency of CD8 ${ }^{+} \mathrm{T}$ cells was reduced in the SILP of Batf $3^{-1-}$ mice (Figure 4a,b), the frequency of $\mathrm{CD}^{+}{ }^{+} \mathrm{T}$ cells was comparable between Batf $3^{-1-}$ mice vs. Batf $3^{+1-}$ littermates (both neonatal and adult), with or without RV infection (Figure $5 \mathbf{a}, \mathbf{b}$ ). We found that adult mice of both genotype exhibited an increase in IFN $\gamma$ production in response to RV infection (Figure $5 \mathrm{c}$ ). In contrast, in neonatal mice, $\mathrm{RV}$ infection provoked $\mathrm{CD} 4^{+} \mathrm{T}$ cells to produce IFN $\gamma$ only in neonatal Batf $3^{+/-}$mice but not in neonatal Batf $3^{-1-}$ mice (Figure 5d). These results suggest a requirement for Batf3-dependent DCs to elicit an anti-RV Th1 response in neonatal mice but not in adult mice. In contrast with the IFN $\gamma$ results, adult Batf $3^{-1-}$ mice exhibited increased 
a

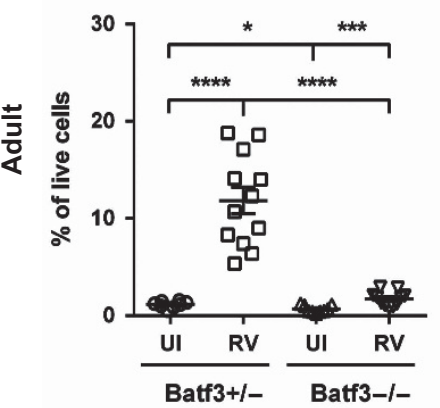

b

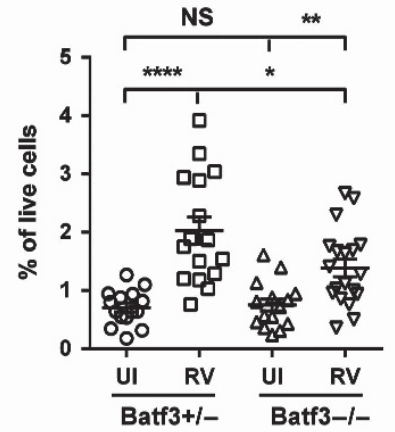

c

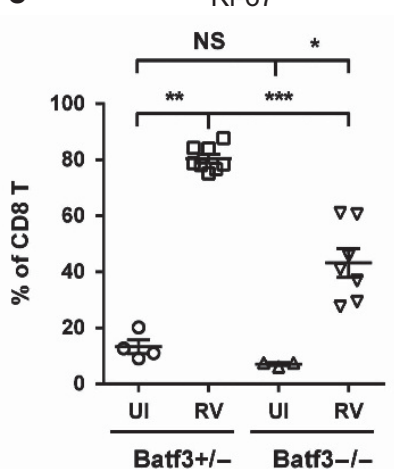

e

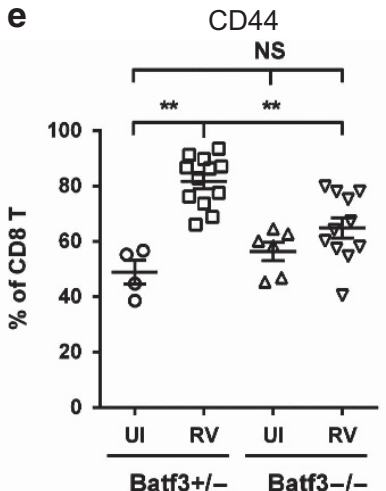

d

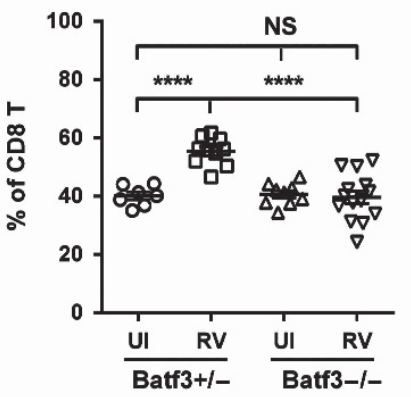

f

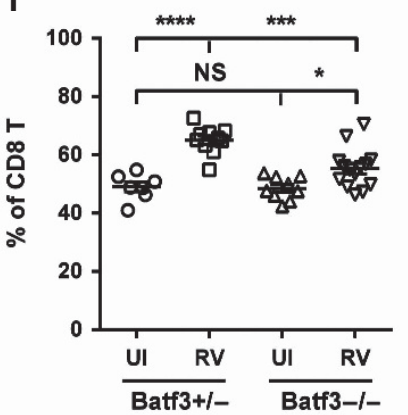

g

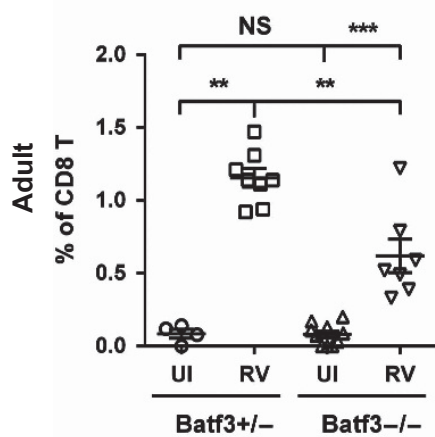

j

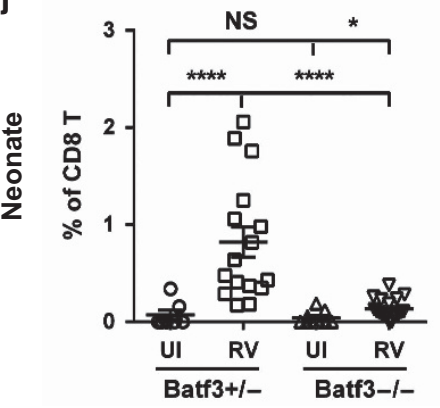

h

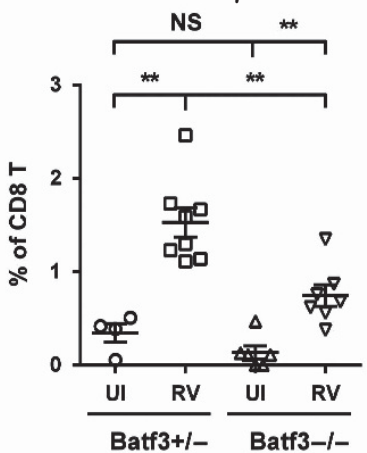

k

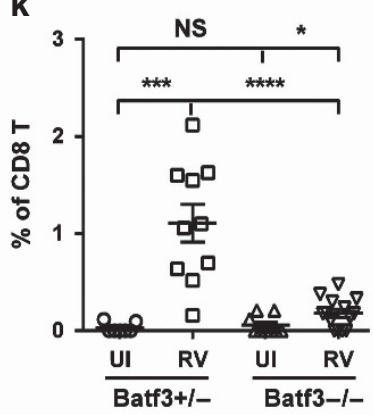

i

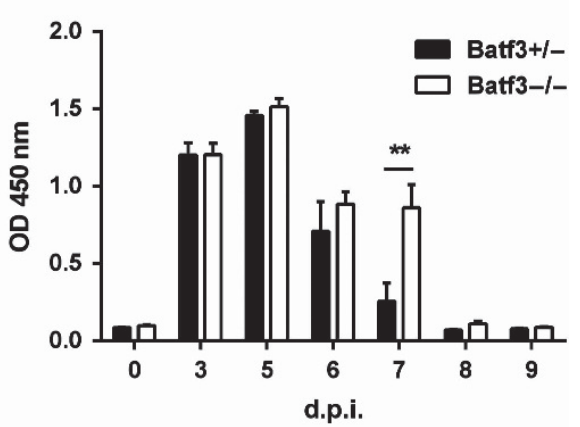

I

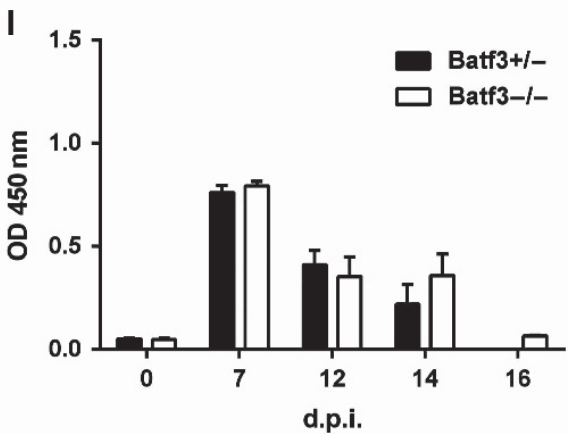

Figure $4 \mathrm{CD}_{103^{+}} \mathrm{CD}_{11 \mathrm{~b}}-\mathrm{DC}$ are required for optimal anti-RV CD8 ${ }^{+} \mathrm{T}$-cell responses in adult and neonatal mice.(a, b) Percentage of CD8 ${ }^{+} \mathrm{T}$ cells as a frequency of small intestinal lamina propria (SILP) mononuclear cells in adult mice (a) and in neonatal mice (b) at 7 days postinfection (d.p.i.). (c, d) Percentage of Ki-67 ${ }^{+}$cells as a frequency of SILP CD8 ${ }^{+}$T cells in adult mice (c) and in neonatal mice (d) after in vitro restimulation with VP6 $6_{357-366}$ peptide at 7 d.p.i. $(\mathbf{e}, \mathbf{f})$ Percentage of $\mathrm{CD} 44^{+}$cells as a frequency of SILP CD8 ${ }^{+}$T cells in adult mice (e) and in neonatal mice (f) after in vitro restimulation with VP6 ${ }_{357-366}$ peptide at 7 d.p.i. (g) Percentage of $\mathrm{VP}_{357-366}^{+}$cells as a frequency of SILP CD8 ${ }^{+}$T cells in adult mice at 7 d.p.i. (h) Percentage of IFN $\gamma^{+}$cells as a frequency of SILP $\mathrm{CD}^{+} \mathrm{T}$ cells in adult mice after in vitro restimulation with $\mathrm{VP} 6_{357-366}$ peptide at 7 d.p.i. (i) Level of rotavirus (RV) antigen in the feces of adult mice measured by enzyme-linked immunosorbent assay (ELISA). (j) Percentage of VP $6_{357-366}^{+}$cells as a frequency of SILP CD8 ${ }^{+}$T cells neonatal mice at 7 d.p.i. (k) Percentage of IFN $\gamma^{+}$cells as a frequency of SILP CD8 ${ }^{+}$T cells in neonatal mice after in vitro restimulation with VP6 ${ }_{357-366}$ peptide at 7 d.p.i. (I) Level of RV antigen in the colon contents of neonatal mice measured by ELISA. UI, uninfected. Results were pooled from three to four independent experiments. Each data point represents a single biological replicate (one mouse). Data are presented as mean \pm s.e.m. (a, b, d, f, k), Student's $t$-test; $(\mathbf{c}, \mathbf{e}, \mathbf{g}-\mathbf{j})$, Mann-Whitney test. ${ }^{\star} P<0.05$, ${ }^{\star \star} P<0.01,{ }^{* \star \star} P<0.001,{ }^{\star \star \star \star} P<0.0001, \mathrm{NS}=$ not significant. Please see Supplementary Figure S4 for further related information. 
a

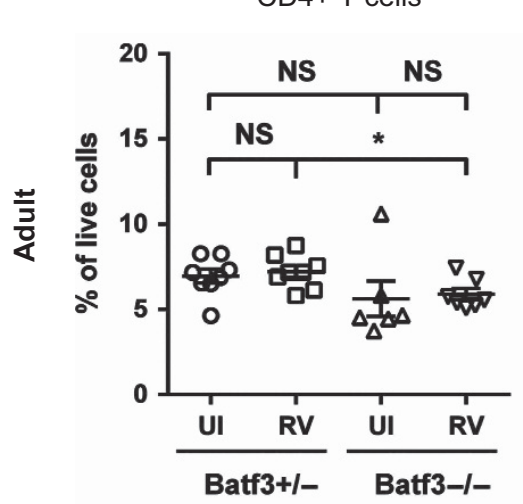

b

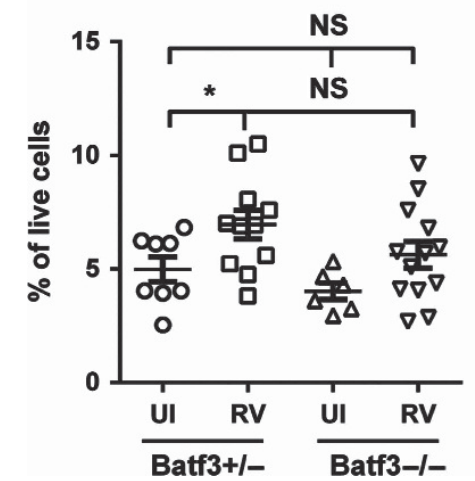

C

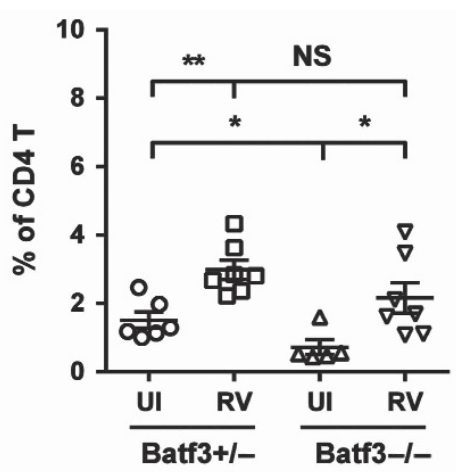

d

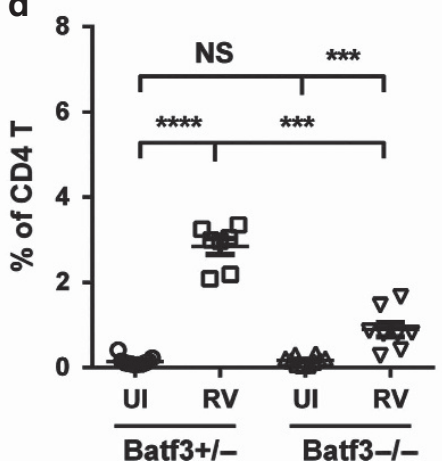

e

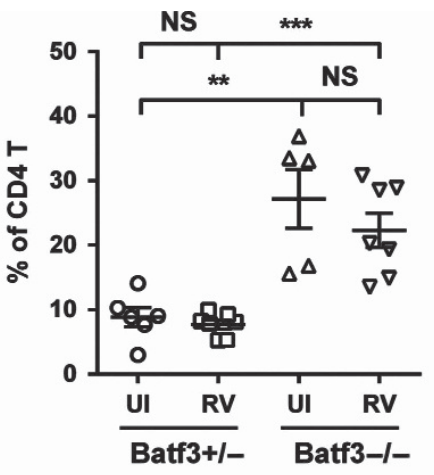

f

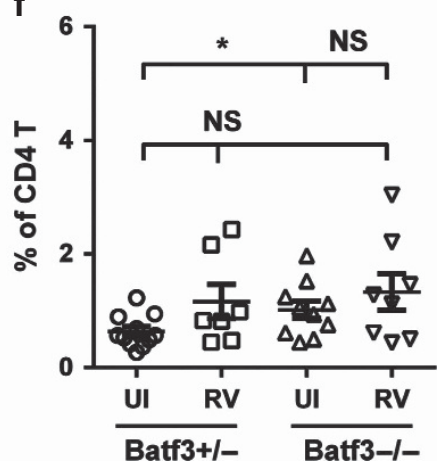

Figure 5 Alteration of Thelper type 1 (Th1) and Th17 responses in adult and neonatal Batf $3^{-/-}$mice. (a, b) Percentage of CD4 ${ }^{+}$T cells as a frequency of small intestinal lamina propria (SILP) mononuclear cells in adult mice (a) and neonatal mice (b) at 7 days postinfection (d.p.i.). (c, d) Percentage of IFN $\gamma^{+}$cells as a frequency of SILP CD4 ${ }^{+}$T cells in adult mice (c) and neonatal mice (d) at 7 d.p.i. (e, f) Percentage of IL-17 A ${ }^{+}$cells as a frequency of SILP CD4 ${ }^{+}$T cells in adult mice (e) and neonatal mice (f) at 7 d.p.i. RV, rotavirus infected; Ul, uninfected. Each data point represents an individual biological replicate (one mouse) pooled from two to three independent experiments. Data are presented as mean \pm s.e.m. (a, d, f), Student's $t$-test; (b, c, e), Mann-Whitney test. ${ }^{\star} P<0.05,{ }^{\star \star \star} P<0.001,{ }^{\star \star \star \star} P<0.0001, \mathrm{NS}=$ not significant.

IL-17-producing $\mathrm{CD}^{+} \mathrm{T}$ cells (Figure 5e), and neonatal Batf $3^{-1-}$ mice exhibited the same trend albeit less pronounced (Figure 5f). Together, these results imply that loss of Batf3 skews the balance of T helper type 1 (Th1) versus Th17 cells.

\section{Intact local and systemic anti-RV IgA responses in cDC-deficient mice}

Th17 cells have been implicated in promoting antigen-specific IgA responses. ${ }^{28}$ Given that Batf3 ${ }^{-1-}$ mice exhibited a trend toward increased Th17 responses (Figure 5e,f), we speculated that Batf3 $3^{-1-}$ mice may display an intact or even enhanced $\mathrm{RV}$-specific IgA response, which could lead to the resolution $\mathrm{RV}$ infection. Indeed, at the time points examined, adult Batf $3^{-1}$ - mice generated RV-specific IgA with similar kinetics as Batf $3^{+/-}$littermates both locally and systemically (Figure 6a,c). In terms of the magnitude of the RV-specific response as expressed in terms of a titer (see Methods section), we found that Batf $3^{-/}$mice produced slightly more IgA in the feces at 14 d.p.i. but less IgA in the serum at 28 d.p.i. compared with Batf3 $3^{+/-}$mice (Figure $6 \mathbf{b}, \mathbf{d}$ ), but overall there was no obvious defect in the IgA response in Batf3 ${ }^{-/}$mice. Moreover, neither local nor systemic anti-RV IgA responses were affected by loss of cDCs in DTx-treated Zbtb46-DTR $\rightarrow$ WT chimeric mice (Figure $\mathbf{6 e - h}$ ). These results suggest that, unlike pDCs, which have an important role in activating $\mathrm{B}$ cells to become RV-specific IgA-producing cells in both humans and mice, ${ }^{19} \mathrm{cDCs}$ are dispensable for generating antigen-specific IgA in adult mice in the context of RV infection.

Finally, similar to adult mice, we found that neonatal mice were able to mount anti-RV IgA responses (Figure 6i-1). In terms of raw optical density measurements, Batf $3^{-1-}$ neonates exhibited a significant increase in the level of anti-RV IgA in the feces (16 d.p.i.) and in the serum (14 and 16 d.p.i.) compared with $\mathrm{Batf3}^{+/-}$neonatal littermates (Figure 6i,k). However, the RV-specific IgA titer in the feces and serum was comparable between $B a t f 3^{+/-}$and $B a t f 3^{-/-}$neonatal mice (Figure 6j,1). These data suggest that humoral antiviral responses are intact in the absence of Batf3-dependent DCs in neonatal mice.

$\mathrm{CD}_{103}{ }^{+} \mathrm{CD11b}{ }^{+} \mathrm{DCs}$ are not required for mounting anti-RV adaptive immune responses

$\mathrm{CD}_{103}{ }^{+} \mathrm{CD} 11 \mathrm{~b}^{+} \mathrm{DCs}$ have been reported as a heterogeneous mixture of pre-DC-derived cDCs and monocyte-derived DCs. ${ }^{7}$ We hypothesized that $\mathrm{CD}_{103}{ }^{+} \mathrm{CD} 11 \mathrm{~b}^{+} \mathrm{DC}$ may have a 

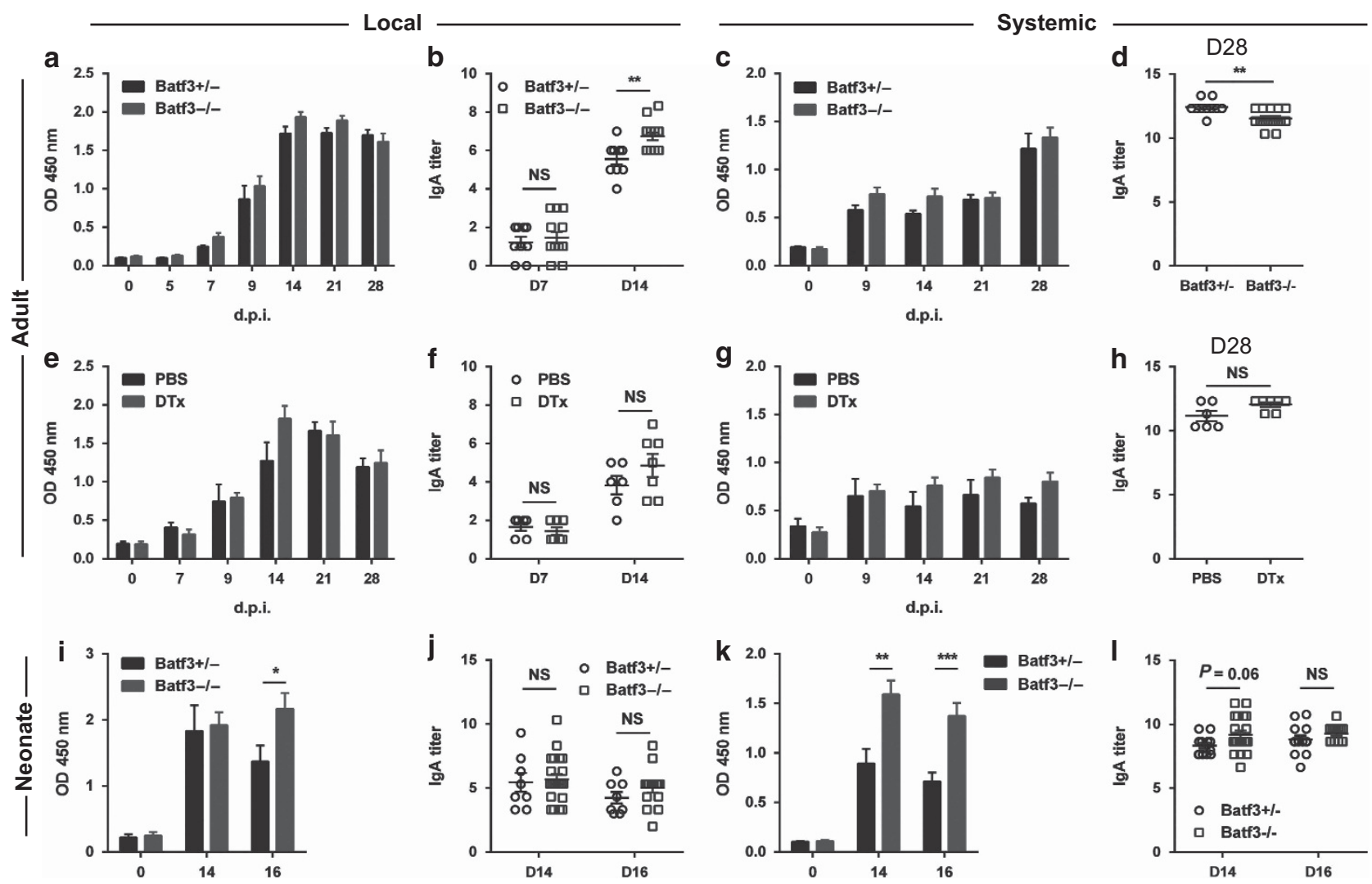

Figure 6 Conventional dendritic cells (DCs) are dispensable for the induction and maintenance of local and systemic antiviral immunoglobulin A (IgA). $(\mathbf{a}, \mathbf{b})$ Level of anti-rotavirus (anti-RV) IgA in the feces measured by enzyme-linked immunosorbent assay (ELISA) in adult mice comparing Batf3 ${ }^{-1}{ }^{-}$vs. Batf $^{+1-}$ littermates (a) and RV-specific IgA titers at 7 and 14 d.p.i. (b). (c, d) Level of anti-RV IgA in the serum measured by ELISA in adult mice comparing Batf3 ${ }^{-1-}$ vs. Batf3 ${ }^{+/-}$littermates (c) and RV-specific IgA titer at 28 d.p.i. (d). (e, f) Level of anti-RV IgA in the feces measured by ELISA in adult mice comparing phosphate-buffered saline (PBS)- vs. diphtheria toxin (DTx)-treated Zbtb46-diphtheria toxin receptor (DTR) $\rightarrow$ wild-type (WT) chimeric mice (e) and RV-specific IgA titers at 7 and 14 d.p.i. (f). (g, h) Level of anti-RV IgA in the serum measured by ELISA in adult mice comparing PBS- vs. DTx-treated Zbtb46-DTR $\rightarrow$ WT chimeric mice (g) and RV-specific IgA titer at 28 d.p.i. (h). (i, j) Level of anti-RV IgA in the feces measured by

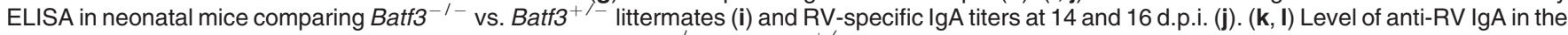
serum measured by ELISA in neonatal mice comparing Batf3 ${ }^{-1-}$ vs. Batf3 ${ }^{+/-}$littermates (k) and RV-specific IgA titers at 14 and 16 d.p.i. (I). UI, uninfected. Each data point represents an individual biological replicate (one mouse) pooled from two to three independent experiments. Data are presented as mean \pm s.e.m. (b, d, j, I), Student's $t$-test; (f, h, i, k), Mann-Whitney test. ${ }^{\star} P<0.05,{ }^{* \star} P<0.01,{ }^{\star \star \star} P<0.001$, NS $=$ not significant.

secondary role in cross-presenting $\mathrm{RV}$ epitope(s) to $\mathrm{CD}^{+}$ $\mathrm{T}$ cells in order to compensate for the loss of $\mathrm{CD} 103^{+} \mathrm{CD}_{11 \mathrm{~b}}{ }^{-}$ DCs in Batf $3^{-1-}$ mice. We tested this hypothesis by examining the RV-specific $\mathrm{CD} 8{ }^{+}$T-cell response in huLangerin-DTA mice, which lack $\mathrm{CD}_{103}{ }^{+} \mathrm{CD}_{11} \mathrm{~b}^{+}$DCs in the SILP (Figure 7a) and MLNs. ${ }^{29} \mathrm{We}$ found that the antigen-specific $\mathrm{CD}^{+}{ }^{+} \mathrm{T}$-cell response was not impaired in huLangerin-DTA mice (Figure $7 \mathbf{b}-\mathbf{e}$ ). In the neonatal setting, the total frequency of SILP CD8 ${ }^{+} \mathrm{T}$ cells post-RV infection in huLangerin-DTA mice was comparable to UI controls (Figure 7f). Although Ki67 staining revealed limited proliferation of $\mathrm{CD} 8^{+} \mathrm{T}$-cells in neonatal huLangerin-DTA mice (Figure $7 \mathbf{g}$ ), we nevertheless observed comparable frequencies $\mathrm{RV}$-specific $\mathrm{CD} 8^{+} \mathrm{T}$ cells between neonatal control and huLangerin-DTA mice (Figure $7 \mathbf{h}$ ). Moreover, viral clearance and IgA production were comparable between adult huLangerin-DTA and control mice (Figure 7i-k). Therefore, although this experiment does not rule out a compensatory role of $\mathrm{CD} 103^{+} \mathrm{CD} 11 \mathrm{~b}^{+}$DCs in Batf $3^{-1-}$ mice, these data imply that $\mathrm{CD}_{103}{ }^{+} \mathrm{CD} 11 \mathrm{~b}^{+}$DCs are dispensable for presenting RV-antigen to $\mathrm{CD} 8{ }^{+} \mathrm{T}$ cells in huLangerin-DTA mice.

\section{DISCUSSION}

In this study, we found that $\mathrm{cDCs}$ are required for optimal CD8 ${ }^{+}$ $\mathrm{T}$-cell responses to RV infection in the small intestine. Furthermore, we demonstrated that Batf3-dependent DCs are the major DC subset responsible for priming $\mathrm{CD} 8^{+}$ $\mathrm{T}$ cells in both adult and neonatal mice. Interestingly, we observed residual $\mathrm{CD}^{+}{ }^{+} \mathrm{T}$-cell proliferation and antigen-driven IFN $\gamma$ production in adult Batf $3^{-1-}$ mice. In sharp contrast to adult $B a t f 3^{-1-}$ mice, neonatal Batf $3^{-1-}$ mice exhibit a complete absence of a $\mathrm{CD} 8^{+} \mathrm{T}$-cell response to $\mathrm{RV}$, indicating that neonatal mice, strictly require Batf3-dependent DCs for priming mucosal $\mathrm{CD}^{+} \mathrm{T}$ cells compared with adult mice. Additionally, local and systemic antiviral IgA production were intact in DTx-treated Zbtb46-DTR chimeric mice, suggesting a dispensable role of cDCs in mounting antiviral IgA responses. 


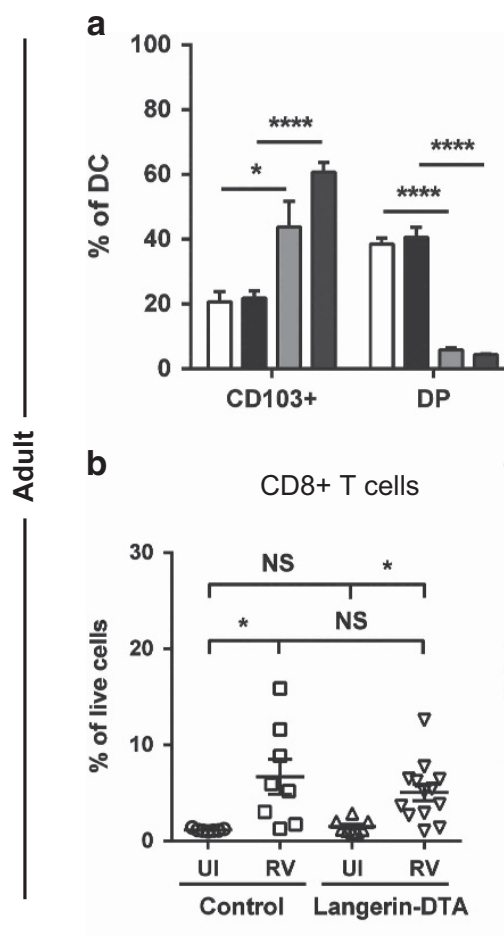

f

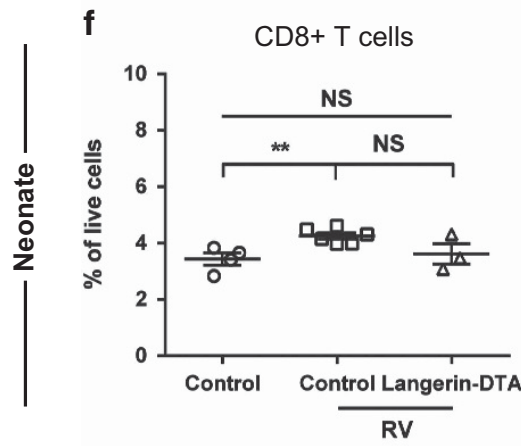

C

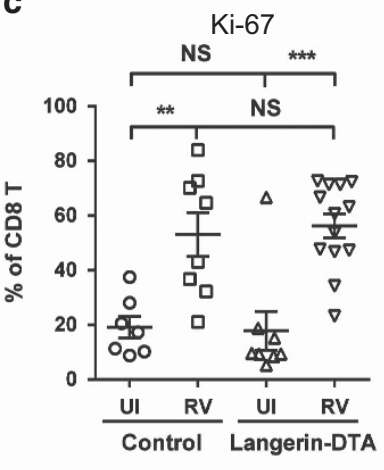

d

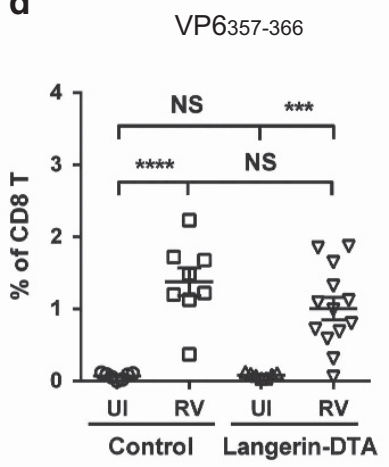

e

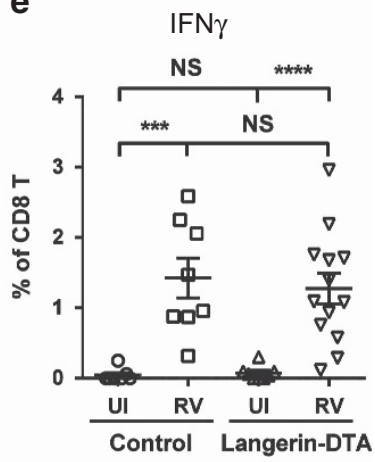

i

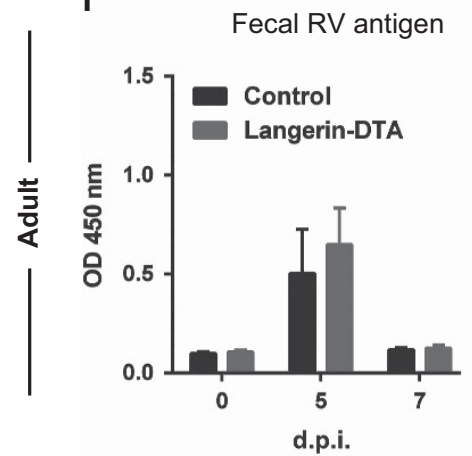

g

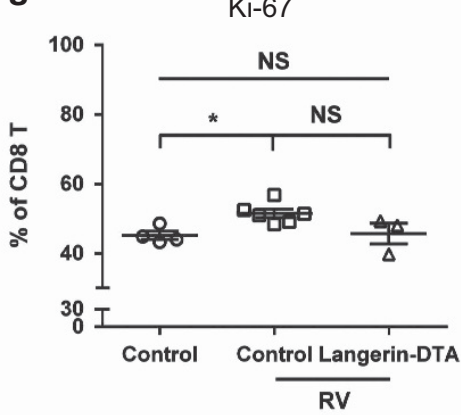

Fecal RV-IgA

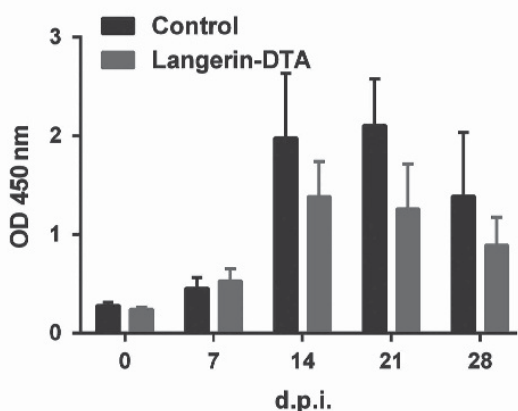

h

h VP6357-366

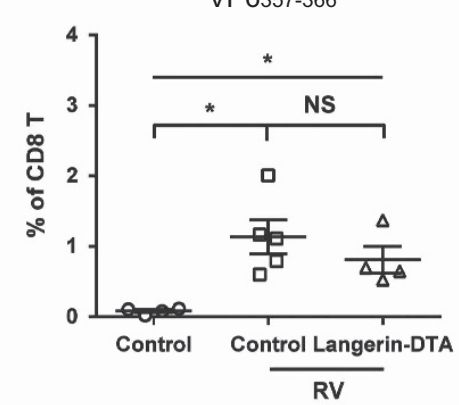

k

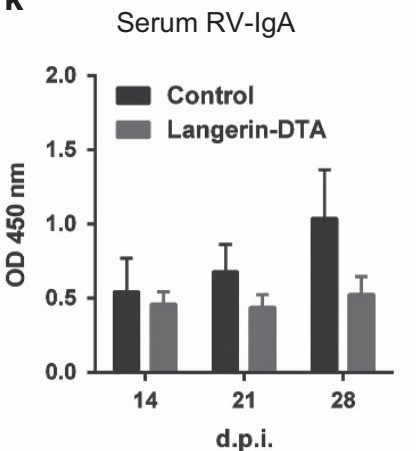

Figure $7 \mathrm{CD} 103^{+} \mathrm{CD}_{11 \mathrm{~b}}{ }^{+}$conventional dendritic cells (DCs) are not required for anti-rotavirus (anti-RV) CD8 ${ }^{+} \mathrm{T}$-cell responses in the small intestinal lamina propria (SILP) of adult and neonatal mice. (a) Percentage of DC subsets as a frequency of DCs in adult huLangerin-DTA mice at 7 d.p.i. (b) Percentage of CD8 ${ }^{+} \mathrm{T}$ cells as a frequency of mononuclear cells in adult huLangerin-DTA mice at 7 d.p.i. (c) Percentage of Ki- $67^{+}$cells as a frequency of CD8 ${ }^{+} \mathrm{T}^{\mathrm{T}}$ cells after in vitro restimulation with VP6 ${ }_{357-366}$ peptide in adult huLangerin-DTA mice at $7 \mathrm{~d}$.p.i. (d) Percentage of VP6 $6_{357-366}^{+} \mathrm{Cells}$ as a frequency of CD8 ${ }^{+}$T cells in adult huLangerin-DTA mice at 7 d.p.i. (e) Percentage of IFN $\gamma^{+}$cells as a frequency of $\mathrm{CD}^{+}{ }^{+}$cells after in vitro restimulation with VP6 ${ }_{357-366}$ peptide in adult huLangerin-DTA mice at 7 d.p.i. (f) Percentage of $\mathrm{CD}^{+}{ }^{+}$cells as a frequency of mononuclear cells in neonatal huLangerin-DTA mice at 7 d.p.i. (g) Percentage of Ki- $67^{+}$cells as a frequency of $\mathrm{CD} 8^{+} \mathrm{T}$ cells after in vitro restimulation with VP $6_{357-366}$ peptide in neonatal huLangerin-DTA mice at 7 d.p.i. (h) Percentage of VP $6_{357-366}^{+}$cells as a frequency of $C D 8^{+} \mathrm{T}$ cells in neonatal huLangerin-DTA mice at 7 d.p.i. (i) Level of RV antigen in the feces in adult huLangerin-DTA mice measured by enzyme-linked immunosorbent assay (ELISA). (j, k) Level of RV-specific IgA in the feces (j) and in the serum (k) in adult huLangerin-DTA mice measured by ELISA. UI, uninfected. Control, huLangerin-DTA ${ }^{-}$littermate. Each data point represents an individual biological replicate (one mouse) pooled from three independent experiments. Data are presented as mean \pm s.e.m. (a, b, d, e), Student's $t$-test; (c, $\mathbf{f}-\mathbf{h})$, Mann-Whitney test. ${ }^{\star} P<0.05,{ }^{\star \star} P<0.01,{ }^{* \star \star} P<0.001,{ }^{* \star \star \star} P<0.0001, \mathrm{NS}=$ not significant. 
As the expression of Zbtb46 is restricted to cDCs but not pDCs or macrophages, the Zbtb46-DTR chimeric mouse model is ideal for studying the role of $\mathrm{CDC}$ in priming $\mathrm{CD} 8^{+} \mathrm{T}$ cells to $\mathrm{RV}$. It has been previously shown that TLR engagement may downregulate Zbtb46 expression, resulting in incomplete depletion of cDC. ${ }^{30}$ To avoid this issue, we treated chimeric mice with DTx 1 day prior to RV infection to predeplete $\mathrm{CDCs}$, and we further eliminated newly generated cDCs by subsequently treating chimeric mice with DTx every 1-2 days. Moreover, we found that depletion of $\mathrm{CDC}$ was equally potent in UI vs. RV-infected chimeric mice (Figure 1b), suggesting that $\mathrm{RV}$ infection does not affect the DC depletion efficiency. To further bolster our findings using the Zbtb46-DTR system, we compared our results with DTx-treated Zbtb46-DTR chimeric mice with DTx-treated CD11c-DTR $\rightarrow$ WT chimeric mice (in this system DTx treatment will deplete DCs and other CD11c-expressing cells). We found that DTx treatment of CD11c-DTR $\rightarrow$ WT chimeric mice resulted in a similar phenotype as DTx treatment of Zbtb46-DTR chimeric mice in terms of $\mathrm{cDC}$ depletion and the impact on the $\mathrm{CD} 8^{+} \mathrm{T}$-cell response (see Supplementary Figure S5a-i). Therefore, although CD11c-DTR $\rightarrow \mathrm{WT}$ chimeric mice are not ideal for studying $\mathrm{cDC}$-specific effects, the parallel phenotypes observed between this system and the Zbtb46-DTR system confirms that the latter chimeras can be reliably used to deplete cDC in the context of RV infection.

Another concern with DTx-based system is that an increased level of splenic neutrophils and monocytes has been reported upon DTx treatment of CD11c-DTR and Zbtb46-DTR chimeric mice. ${ }^{24,31}$ We found that the frequency of granulocytes in the SILP was unaltered after DTx treatment in Zbtb46-DTR chimeric mice with or without RV infection, although interestingly, an increase in granulocytes was observed in CD11cDTR chimeric mice (see Supplementary Figure S5j). Therefore, the use of Zbtb46-DTR chimeric mice has provided us with the opportunity to compare the RV-specific $\mathrm{CD} 8{ }^{+} \mathrm{T}$-cell response in mice that lack all cDC (Zbtb46-DTR chimeric mice), and when coupled with non-DTx systems that lack select subsets of cDC (Batf $3^{-1-}$ mice), we may discover which $\mathrm{cDC}$ are correlated with $\mathrm{CD}^{+}{ }^{+} \mathrm{T}$-cell responses to RV infection.

We report here that Batf3-dependent DCs are the principal DC responsible for cross-presenting RV antigen to intestinal $\mathrm{CD}^{+} \mathrm{T}$ cells. Our results are consistent with Cerovic et al. ${ }^{25}$ who demonstrated that lymph-borne $\mathrm{CD} 103^{+} \mathrm{CD} 11 \mathrm{~b}^{-}$ CD $8 \alpha^{+}$DCs can cross-prime CD ${ }^{+}$T cells against intestinal epithelial cell (IEC)-derived cellular antigens within the MLNs. As mentioned, some $\mathrm{CD}^{+} \mathrm{T}$ cells can still undergo proliferation in adult $B a t f 3^{-1-}$ mice upon viral challenge. This could either be due to restoration of $\mathrm{CD}_{103}{ }^{+} \mathrm{CD} 11 \mathrm{~b}^{-}$ DCs following RV infection or alternatively a compensatory cell may prime $\mathrm{CD} 8^{+} \mathrm{T}$ cells in adult $\mathrm{Batf} 3^{-1-}$ mice. In support of the former possibility, Tussiwand et al. ${ }^{32}$ reported that $\mathrm{CD} 103{ }^{+} \mathrm{CD}_{11 \mathrm{~b}}{ }^{-}$DCs can be restored upon IL-12 administration or pathogen-induced IL-12. However, we found no evidence of a restoration of $\mathrm{CD}_{103}{ }^{+} \mathrm{CD} 11 \mathrm{~b}^{-}$DCs in the SILP or $\mathrm{CD}_{103}{ }^{+} \mathrm{CD} 11 \mathrm{~b}^{-} \mathrm{mDC}$ and $\mathrm{CD} 8 \alpha^{+} \mathrm{CD} 11 \mathrm{~b}^{-}$rDCs in the
MLNs during the RV infection time course in Batf $3^{-/-}$adult mice. Thus the compensatory IL-12-mediated development of Batf3-independent $\mathrm{CD} 103{ }^{+} \mathrm{CD}_{11} \mathrm{~b}^{-}$DC appears not to be a feature of the RV system during the first week of infection, although it could be the case at earlier time points.

We favor the hypothesis that an alternative APC can induce some proliferation of RV-specific $\mathrm{CD} 8^{+} \mathrm{T}$ cells in Batf $3^{-1-}$ mice. Compared with Batf $3^{+/-}$littermates, the residual $\mathrm{CD} 8^{+}$ $\mathrm{T}$-cell response to RV correlates with significant increases in $\mathrm{CD}_{103}{ }^{+} \mathrm{CD}_{11 \mathrm{~b}}{ }^{+}$and $\mathrm{CD} 103^{-} \mathrm{CD}_{11 \mathrm{~b}}{ }^{+} \mathrm{mDC}$ in the MLN as well as $\mathrm{CD} 103^{-} \mathrm{CD}_{11 \mathrm{~b}^{+}}$DCs in the SILP (Supplementary Figure S3). As these DCs are not increased in DTx-treated Zbtb46-DTR $\rightarrow$ WT chimeric mice (Supplementary Figure S1), which completely lack a $\mathrm{CD} 8{ }^{+} \mathrm{T}$-cell response to $\mathrm{RV}$, the residual $\mathrm{CD} 8^{+} \mathrm{T}$-cell response to $\mathrm{RV}$ in adult $\mathrm{Batf} 3^{-1-}$ mice may therefore be due to compensatory increases in $\mathrm{CD} 103^{-}$ $\mathrm{CD}_{11 \mathrm{~b}}{ }^{+}$DCs in the SILP and/or $\mathrm{CD}_{103}{ }^{+} \mathrm{CD} 11 \mathrm{~b}^{+}$and $\mathrm{CD}_{103}{ }^{-} \mathrm{CD} 11 \mathrm{~b}^{+}$mDCs in the MLN. Finally, another possible explanation for the residual $\mathrm{CD}^{+}{ }^{+} \mathrm{T}$-cell response in adult Batf $3^{-1-}$ mice is that atypical/non-professional APCs such as IECs may also present antigens to T cells. ${ }^{33}$ As RV replicates in IECs, it would be interesting to know whether IECs can present viral antigens to $\mathrm{CD} 8^{+} \mathrm{T}$ cells in the absence of Batf3dependent DCs.

Neonates are highly susceptible to infections with pathogens, such as RV. However, the mechanism(s) responsible for impaired infant immunity remain elusive. It has been reported that neonatal $\mathrm{T}$ cells are prone to a Th2 bias, ${ }^{34}$ and this phenomenon could be explained by a lack of maturity of neonatal DCs (i.e., lower level of major compatibility complex (MHC) class II, co-stimulatory molecule CD86 and key cytokines such as IL-12, compared with adult DCs). ${ }^{35}$ However, we found that neonatal mice are able to elicit a robust antigenspecific $\mathrm{CD} 8^{+}$T-cell response, including the production of IFN $\gamma$, indicating that neonatal DCs are fully capable of priming $\mathrm{CD}^{+}{ }^{-} \mathrm{T}$ cells during infection. On the other hand, unlike adult Batf $3^{-1-}$ mice, Batf $3^{-1-}$ neonates were not able to mount antigen-specific $\mathrm{CD} 8{ }^{+} \mathrm{T}$-cell responses. As SILP T cells from neonatal mice are relatively naive compared with adult $\mathrm{T}$ cells, which can be antigen-experienced, we hypothesize that the activation threshold for neonatal $\mathrm{T}$ cells may be higher, and adequate priming would require a particularly specialized DC subtype, such as Batf3-dependent DCs.

In spite of the absence of an antigen-specific $\mathrm{CD} 8{ }^{+} \mathrm{T}$-cell response to RV infection, $B a t f 3^{-1-}$ neonatal mice can nevertheless clear RV with similar kinetics as control mice, suggesting other antiviral responses beyond $\mathrm{CD}^{+} \mathrm{T}$-cell responses exist to resolve RV infection. It is likely that innate immunity has a key role in controlling RV infection in neonates. For example, IL-22 and IFN $\lambda$ produced by type 3 innate lymphoid cells can synergistically stimulate IEC antiviral responses thereby contributing to $\mathrm{RV}$ clearance in neonates. ${ }^{23}$ We detected IL-22 in neonatal SILP Ror $\gamma \mathrm{t}^{+}$cells at the steady state by flow cytometry and by reverse transcriptase-PCR (RTPCR), although these levels were not greatly increased after RV infection (see Supplementary Figure S6a-c). As a positive 
control, IL-22 induction was detected in the colonic tissues from mice infected with C. rodentium at 6 d.p.i by quantitative PCR (see Supplementary Figure S6c). We also detected a marked upregulation of IFN $\lambda$ in intestinal epithelial lymphocytes after RV infection that was comparable between Batf $3^{+/-}$and Batf $3^{-1-}$ neonatal mice (see Supplementary Figure S6d). Therefore, early innate cytokine production is intact in $\mathrm{Batf}^{-1-}$ neonatal mice, possibly explaining the normal viral clearance in these mice.

In addition to IL-22 and IFN $\lambda$, pDCs from 7-day postnatal mice are capable of producing similar amounts of type I IFN as their adult counterparts, ${ }^{35}$ making type I IFN another candidate for defense against RV infection in neonates. This type I IFN production may promote neonatal RV-specific IgA responses, and indeed, the local and systemic anti-RV IgA responses in Batf $3^{-1-}$ neonatal mice are not only intact but were in fact slightly more robust than the Batf $3^{+/-}$neonatal mice. However, it is important to note that RV-specific IgA is the predominant antibody species in lacteal secretions from mice naturally infected with RV or experimentally infected through the oral route; ${ }^{36}$ thus passively acquired IgA may contribute to the presence of RV-specific IgA in neonates and help resolve $\mathrm{RV}$ infection. It would be interesting to determine whether the robust IgA response in neonates is due to an elevated type I IFN production by $\mathrm{pDCs}$, in the absence of Batf3-dependent cDCs.

In addition to impaired $\mathrm{CD} 8^{+}$T-cell immunity in Batf $3^{-1-}$ mice, polyclonal $\mathrm{CD}^{+}{ }^{+} \mathrm{T}$-cell cytokine production is also skewed. During L. major infection, it has been reported that the protective Th1 immune response is severely hindered in Batf $3^{-1-}$ mice, correlating with impaired IL-12 production and a reduction in $\mathrm{CD}_{103}{ }^{+}$DC numbers. ${ }^{12}$ Consistent with previous studies, ${ }^{37,38}$ we found that intestinal Th1 responses were diminished in adult Batf $3^{-1-}$ mice in the steady state and neonatal Batf $3^{-1-}$ mice challenged with RV. On the other hand, consistent with previous results, ${ }^{38}$ we found that both adult and neonatal Batf $3^{-1-}$ mice exhibit a trend toward increased Th17 cell frequency compared with Batf $3^{+/-}$ littermates. Aychek et al. $^{39}$ have reported that during C. rodentium infection, colonic $\mathrm{CD} 103^{-} \mathrm{CD} 11 \mathrm{~b}^{+} \mathrm{DC}$ - and macrophage-derived IL-23 can suppress IL-12 production by $\mathrm{CD}_{103}{ }^{+} \mathrm{CD}_{11 \mathrm{~b}}{ }^{-} \mathrm{DCs}$, resulting in the generation of IFN $\gamma$ producing ex-Th17 cells. We hypothesize that, in the absence of Batf3-dependent DCs, diminished $\mathrm{CD}_{103}{ }^{+} \mathrm{CD} 11 \mathrm{~b}^{-}$DCderived IL-12 and enhanced $\mathrm{CD}_{103}{ }^{-} \mathrm{CD}_{11 \mathrm{~b}}{ }^{+}$DC-derived IL-23 results in skewing of cytokines produced by Th cells. Further investigations are need to address this possibility, with the caveat that a role for Batf3-dependent DCs in modulating intestinal Th responses is likely influenced by the choice of stimuli/pathogen and the age of the mice (neonate vs. adult).

In adults, the antiviral IgA response in $\mathrm{CDC}$-deficient mice as well as Batf3-deficient mice is comparable to that of littermate controls. This suggests that IgA responses can occur in the absence of pre-DC derived cDCs. The normal humoral response we observed in Batf $3^{-1-}$ mice is consistent with the results from Hildner et al. ${ }^{3}$ who found that normal WNV-specific $\operatorname{IgM}$ and $\operatorname{IgG}$ responses were induced in
WNV-challenged Batf3 $3^{-1-}$ mice. We speculate that the antiviral IgA response in $\mathrm{cDC}$-deficient mice may compensate for the abrogated RV-specific $\mathrm{CD} 8{ }^{+} \mathrm{T}$-cell response, resulting in only a transient delay in viral clearance.

Our study mainly focused on characterizing the function of DC subsets in primary RV infection. However, it would be interesting to expand our study to examine how cDC subsets affect secondary RV challenge, eventually translating our study toward a vaccine design strategy. The two current licenced RV vaccines on the market, Rotarix and RotaTeq, reduce RV-related morbidity and mortality in developed countries; however, they are not as efficient in resource-poor countries. ${ }^{27,40}$ Additionally, vaccine development has been highly empirical, leaving large gaps in our understanding of how they induce protection. ${ }^{27}$ Boosting antiviral CD8 ${ }^{+}$T-cell responses by modulating Batf3-dependent DCs might help generate long-term T-cell memory in non-responsive individuals.

\section{METHODS}

Mice. WT C57BL/6 (Charles River Laboratory, St. Constant, QC, Canada), Zbtb46-DTR (gift from Dr Kenneth Murphy, Washington University, USA), B6.129S(C)-Batf ${ }^{\mathrm{tm} 1 \mathrm{Kmm} / J}\left(\right.$ Batf $\left.^{-{ }^{-1-}}\right)$ (The Jackson Laboratory, Bar Harbor, ME, USA), B6.FVB-Tg(CD207-Dta)312Dhka/J (huLangerin-DTA) (The Jackson Laboratory), and CD11c-DTR mice (The Jackson Laboratory) were housed in the University of Toronto Division of Comparative Medicine under specific pathogen-free conditions. All experiments were approved by the University Animal Care Committee. Purchased Batf $3^{-7-}$ mice were first bred with WT mice $\left(\right.$ Batf $\left.3^{+/+}\right)$to generate Batf $3^{+/-}$heterozygous F1 offspring. Subsequently Batf $3^{+}-$F1 mice were back-crossed with Batf $3^{-1-}$ mice to generate $B a t f 3^{+/-}$and $B a t f 3^{-1-}$ littermates for experimental use. The purchased huLangerin-DTA ${ }^{+1+}$ mice were first bred with WT mice (huLangerin-DTA ${ }^{-1-}$ ) to generate huLangerin-DTA ${ }^{+1-}$ heterozygous F1 offspring. Subsequently, huLangerin-DTA ${ }^{+/-}$F1 mice were back-crossed with WT mice to generate huLangerin-DTA and huLangerin-DTA ${ }^{-}$littermates for experimental use.

Antibodies and flow cytometry. Anti-mouse CD $3 \varepsilon$ APC eFluor780 (17A2), CD103 APC (2E7), CD4 APC (RM4-5), CD4 FITC (RM4-5), CD8 $\alpha$ FITC (53-6.7), CD11c FITC (N418), CD44 PercpCyanine 5.5 (1M7), CD45R (B220) Percp-Cyanine 5.5 (RA3-6B2), IFN $\gamma$ PE-Cyanine 7 (XMG1.2), CD11c PE-Cyanine 7 (N418), MHC II (I-A/I-E) eFluor 450 (M5/114.15.2), anti-mouse/rat Ki-67 eFluor 450 (SolA15), and anti-mouse IL-22 PE (1H8PWSR), ROR $\gamma$ t APC (B2D) were purchased from eBioscience (San Diego, CA). Anti-mouse PE/Dazzle 594 F4/80 (BM8), Brilliant Violet 711 CD8 $\alpha$ (53-6.7), Brilliant Violet 605 IL-17A (TC 11-18H10.1), and anti-mouse/human Brilliant Violet 605 CD11b (M1/70) were purchased from Biolegend (San Diego, CA). Live/Dead fixable Aqua was purchased from Life Technologies (Carlsbad, CA). After Live/Dead Aqua staining, cells were washed and then blocked with purified anti-Fc $\gamma$ RII/III monoclonal antibody (2.4G2). All surface stains were performed in PBS with $2 \%$ fetal bovine serum. Intracellular staining was performed using a Cytofix/Cytoperm Kit (BD Biosciences, Baltimore, MD). All stained samples were acquired on a BD LSR II or LSR Fortessa as appropriate. FlowJo software (Tree Star, Ashland, OR) was used for fluorescence-activated cell sorting data analysis.

BM chimeric mice and DTx treatment. BM cells $\left(2-4 \times 10^{6}\right)$ collected from the femurs and tibia of Zbtb46-DTR or CD11c-DTR mice were injected intravenously into WT C57BL/6 mice that had been lethally irradiated $(2 \times 550 \mathrm{cGy})$. Recipient mice were left for $8-10$ weeks to 
reconstitute and were given water supplemented with neomycin sulfate $\left(2 \mathrm{gl}^{-1}\right.$; BioShop, Burlington, ON, Canada) for the first 2 weeks. Twenty nanograms per gram body weight of DTx (List Biological Laboratories, Campbell, CA) was injected intraperitoneally into Zbtb46-DTR $\rightarrow$ WT chimeric mice 1 day prior to RV inoculation, and DTx injections were then repeated every day for short-term experiments (mice were killed at 7 d.p.i for T-cell assay) or every other day for long-term experiments (mice were killed at 28 d.p.i. for enzyme-linked immunosorbent assay (ELISA) assays). Both treatment strategies resulted in the transient delay of RV antigen clearance at 7 d.p.i., indirectly confirming DC depletion. To exclude any contributions to our phenotype caused by the gut microbiome, DTx- and PBS-treated Zbtb46-DTR $\rightarrow$ WT chimeric mice were housed in the same cage for both RV-infected and UI conditions. Seven nanograms per gram body weight of DTx was injected intraperitoneally into CD11c-DTR $\rightarrow$ WT chimeric mice 1 day prior to RV inoculation and DTx injections were then repeated every 2 days to maintain DC ablation.

RV mouse infections. The virulent WT, non-cell-culture-adapted murine RV strain ECw was used to infect mice. One single virus stock was used in these studies. RV stock was prepared as intestinal homogenates, and the $50 \%$ diarrhea dose $\left(\mathrm{DD}_{50}\right)$ of the $\mathrm{ECw}$ virus stock was determined for WT C57BL/6 neonatal mice as previously described. ${ }^{41}$ The day prior to oral gavage with RV, adult and neonatal mice were transferred to biosafety level 2 facilities for the duration of all studies. UI mice were housed separately in BSL1 facilities in the University of Toronto Division of Comparative Medicine. Adult mice (6-8 weeks of age) were orally gavaged with $10^{4} \mathrm{DD}_{50} \mathrm{ECw}$ in $100 \mu \mathrm{l}$ Hank's Balanced Salt Solution containing $1 \mathrm{~mm} \mathrm{CaCl}_{2}$ and $0.5 \mathrm{~mm}$ $\mathrm{MgCl}_{2}$ after oral administration of $100 \mu \mathrm{l}$ of $1.33 \%$ sodium bicarbonate to neutralize stomach acidity. Fecal pellets were collected from each mouse on the day of challenge and on subsequent days. Serum samples were collected with Microvette Capillary blood collection tubes (Sarstedt, Nümbrecht, Germany) according to the manufacturer's instructions. Fecal and serum samples were stored frozen at $-20^{\circ} \mathrm{C}$ until assayed. For use in the ELISAs, $10 \%$ (wt/vol) stool suspensions were prepared with PBS containing $0.1 \%$ sodium azide (Merck Millipore, Darmstadt, Germany). For neonatal infections, neonatal (35 days postnatal) $B a t f 3^{+/-}$and $B a t f 3^{-1-}$ littermates were fostered with a lactating CD1 dam 1-2 days prior to RV inoculation. The pups remained with the $\mathrm{CD} 1 \mathrm{dam}$ for the duration of the experiment. Neonatal mice were given an oral dose of $5 \times 10^{3} \mathrm{DD}_{50}$ ECw in $5 \mu \mathrm{l}$ Hank's Balanced Salt Solution containing $1 \mathrm{~mm} \mathrm{CaCl}_{2}$ and $0.5 \mathrm{~mm}$ $\mathrm{MgCl}_{2}$. On the day of harvest, neonatal mice were killed by decapitation (7 d.p.i.) or $\mathrm{CO}_{2}$ asphyxiation (12, 14, 16 d.p.i.). Fecal pellets or colon contents were collected and were stored frozen at $-20{ }^{\circ} \mathrm{C}$ until assayed. Serum was collected by intracardiac puncture.

Bacterial infections. In all, $2 \times 10^{9}$ colony-forming units of an overnight culture of $C$. rodentium strain DBS100 was used to infect 610 -week-old WT mice by oral gavage as a positive control for detecting IL-22 production.

Detection of RV antigen and anti-RV IgA by ELISA. ELISA to detect $\mathrm{RV}$ antigen, RV-specific fecal or serum IgA was performed as previously described. ${ }^{42}$ For measurement of $\mathrm{RV}$-specific IgA titer, we adapted an assay previously described. ${ }^{43}$ Briefly, ELISA plates were coated overnight with sheep-anti-RV Ab (Bio-rad, Raleigh, NC). The plates were then blocked and incubated with inactivated Simian Rotavirus SA11 antigen (Microbix, Mississauga, ON, Canada). After washing, the plates were incubated with twofold serial dilutions of serum samples or fecal supernatant. Horseradish peroxidaseconjugated goat anti-mouse IgA (SouthernBiotec, Birmingham, $\mathrm{AL})$ was applied to capture IgA and then the plates were then developed by TMB solution (BioShop). The titer of $\operatorname{IgA}$ in a serum or fecal sample was defined as $\log _{2}$-transformed reciprocal of the last dilution exceeding an optical density of the value which was twice the optical density of blank wells (blanks were those wells without added serum or fecal samples) (IgA titer $=\log _{2}$ (1/last positive dilution)). To be accepted for analysis, the titer of an internal positive control in a plate could not differ by more than one dilution from plate to plate.

Cell isolation. For analysis of MLN cells, organs were mashed through a 70-mm cell strainer followed by PBS washing. SILP preparation was performed as previously described. ${ }^{42}$ Briefly, small intestines were dissected and cleaned in situ of mesenteric fat and Peyer's patches were removed. Small pieces of the intestine were then thoroughly washed and EDTA solution was used to remove IELs. The remaining SILP fraction was then digested with collagenase IV (Sigma-Aldrich, St. Louis, MO) and lymphocytes were enriched by Percoll gradient (GE Healthcare, Uppsala, Sweden). For IELs, after washing with an EDTA solution, IELs were enriched by Percoll gradient. Given the inherent variability and potential underestimations in true cell yield in gut preparations, for the most part we enumerated cellular compartments based on both frequency and absolute numbers.

\section{T-cell assays}

Intracellular staining. To enumerate the number of cytokine-secreting $\mathrm{T}$ cells, intracellular staining was performed as previously described. ${ }^{26,42}$ Briefly, after Percoll gradient, lymphocytes were incubated at $37^{\circ} \mathrm{C}$ in complete medium supplemented with recombinant human IL-2 (100 $\mathrm{U} \mathrm{ml}^{-1}$; R\&D Systems, Minneapolis, MN) and GolgiPlug $\left(1 \mu \mathrm{ml}^{-1}\right.$; BD Biosciences). Cells were stimulated with either phorbol 12-myristate 13 -acetate ( $20 \mathrm{ng} \mathrm{ml}^{-1}$; Sigma-Aldrich)ionomycin $\left(500 \mathrm{ng} \mathrm{ml}^{-1}\right.$; Sigma-Aldrich) for $4 \mathrm{~h}$ or $\mathrm{VP6}_{357-366}$ peptide (VGPVFPPGM) $\left(2 \mu \mathrm{g} \mathrm{ml}^{-1}\right.$, Genemed Synthesis, San Antonio, TX) for $6 \mathrm{~h}$ followed by fluorescence-activated cell sorter staining.

Tetramer staining. $\mathrm{VP} 6_{357-366^{-}}$-biotin was synthesized by the NIH tetramer facility and then conjugated with PE-streptavidin (Life Technologies) according to the manufacturer's instructions. After Live/dead Aqua staining, cells were incubated with VP6-PE tetramer for $1 \mathrm{~h}$ at $4{ }^{\circ} \mathrm{C}$, followed by other surface staining.

RNA isolation and quantitative RT-PCR. SILP tissues (stored in RNAlater (QIAGEN, Hilden, Germany) at $-20^{\circ} \mathrm{C}$ ) or fresh cell pellets were used for RNA extraction. RNA was isolated with Trizol reagent according to the manufacturer's instructions (Thermo Fisher Scientific, Waltham, MA). Genomic DNA was removed with the TURBO DNA-free Kit (Thermo Fisher Scientific). RNA was reversetranscribed into cDNA with the SuperScript IV Reverse Transcriptase Kit (Thermo Fisher Scientific). RT-PCR was performed with SYBR Green Master Mix (Thermo Fisher Scientific) and was run on a CFX384 Touch Real-Time PCR Detection System (Bio-Rad). The relative expression of genes was calculated with the formula $2^{-\Delta \Delta \mathrm{Ct}}$. Murine RPL19 was used as an endogenous control housekeeping gene.

Real-time PCR primer sequences

\begin{tabular}{|c|c|c|}
\hline Gene & Forward sequence & Reverse sequence \\
\hline IFN $\lambda 2 / 3$ & $\begin{array}{l}\text { 5'-AGCTGCAGGCCTTCAA } \\
\text { AAAG-3' }\end{array}$ & $\begin{array}{l}\text { 5'-TGGGAGTGAATGTGG } \\
\text { CTCAG-3' }\end{array}$ \\
\hline IL-22 & $\begin{array}{l}\text { 5'-CATGCAGGAGGTGG } \\
\text { TACCTT-3' }\end{array}$ & $\begin{array}{l}\text { 5'-CAGACGCAAGCATTा } \\
\text { CTCAG-3' }\end{array}$ \\
\hline mRPL19 & $\begin{array}{l}\text { 5'-GCATCCTCATGGAGC } \\
\text { ACAT-3' }\end{array}$ & $\begin{array}{l}\text { 5'-CTGGTCAGC CAGGA } \\
\text { GCTT-3' }\end{array}$ \\
\hline
\end{tabular}

Statistics. Comparisons of data were analyzed by Student's $t$-test (normal distribution) or Mann-Whitney non-parametric test 
(non-gaussian distribution) with the GraphPad Prism 6.0 program (San Diego, CA). Data are presented as mean values \pm s.e.m. $P<0.05$ was considered significant.

SUPPLEMENTARY MATERIAL is linked to the online version of the paper at http://www.nature.com/mi

\section{ACKNOWLEDGMENTS}

We thank Dr Harry Greenberg (Stanford University) for providing the ECW rotavirus strain. We thank NIH tetramer facility for supplying VP6-biotin monomer. We thank Dionne White in the Flow Cytometry core facility for technical supports and Stacy Nichols in the Division of Comparative Medicine for mouse husbandry at University of Toronto. We thank Nichole Escalante (University of Toronto) for tissues infected with Citrobacter rodentium. This work was funded by a grant from the Canadian Institutes of Health Research (MOP 67157).

\section{AUTHOR CONTRIBUTION}

T.S. performed the experiments and interpreted the data; T.S., C.L., and O.L.R. contributed to standardize and optimize some assays; L.A.W. contributed to some RT-PCR experiments; D.J.P. and J.L.G. designed the experiments and interpreted the data; T.S. and J.L.G. wrote the manuscript.

\section{DISCLOSURE}

The authors declared no conflict of interest.

(c) 2017 Society for Mucosal Immunology

\section{REFERENCES}

1. Murphy, K.M. Transcriptional control of dendritic cell development. Adv. Immunol. 120, 239-267 (2013).

2. Satpathy, A.T. et al. Zbtb46 expression distinguishes classical dendritic cells and their committed progenitors from other immune lineages. J. Exp. Med. 209, 1135-1152 (2012).

3. Hildner, K. et al. Batf3 deficiency reveals a critical role for CD8alpha + dendritic cells in cytotoxic T cell immunity. Science 322, 1097-1100 (2008).

4. Mashayekhi, M. et al. CD $8 \alpha(+)$ dendritic cells are the critical source of interleukin-12 that controls acute infection by Toxoplasma gondii tachyzoites. Immunity 35, 249-259 (2011).

5. Persson, E.K. et al. IRF4 transcription-factor-dependent CD103(+) $\mathrm{CD} 11 \mathrm{~b}(+)$ dendritic cells drive mucosal $\mathrm{T}$ helper 17 cell differentiation. Immunity 38, 958-969 (2013).

6. Schlitzer, A. et al. IRF4 transcription factor-dependent CD11b + dendritic cells in human and mouse control mucosal IL-17 cytokine responses. Immunity 38, 970-983 (2013).

7. Satpathy, A.T. et al. Notch2-dependent classical dendritic cells orchestrate intestinal immunity to attaching-and-effacing bacterial pathogens. Nat. Immunol. 14, 937-948 (2013).

8. Grajales-Reyes, G.E. et al. Batf3 maintains autoactivation of Irf8 for commitment of a CD $8 \alpha(+)$ conventional DC clonogenic progenitor. Nat. Immunol. 16, 708-717 (2015).

9. Edelson, B.T. et al. Peripheral CD103 + dendritic cells form a unified subset developmentally related to CD8alpha + conventional dendritic cells. J. Exp. Med. 207, 823-836 (2010).

10. Krueger, P.D., Kim, T.S., Sung, S.S., Braciale, T.J. \& Hahn, Y.S. Liverresident CD103 + dendritic cells prime antiviral CD8 + T cells in situ. J. Immunol. 194, 3213-3222 (2015).

11. Torti, N., Walton, S.M., Murphy, K.M. \& Oxenius, A. Batf3 transcription factor-dependent DC subsets in murine CMV infection: differential impact on T-cell priming and memory inflation. Eur. J. Immunol. 41, 2612-2618 (2011).

12. Martínez-López, M., Iborra, S., Conde-Garrosa, R. \& Sancho, D. Batf3dependent CD103 + dendritic cells are major producers of IL-12 that drive local Th1 immunity against Leishmania major infection in mice. Eur. J. Immunol. 45, 119-129 (2015).
13. Waithman, J. et al. Resident CD8(+) and migratory CD103(+) dendritic cells control CD8 T cell immunity during acute influenza infection. PLOS One 8, e66136 (2013).

14. Ruckwardt, T.J., Malloy, A.M., Morabito, K.M. \& Graham, B.S. Quantitative and qualitative deficits in neonatal lung-migratory dendritic cells impact the generation of the CD8 + T cell response. PLoS Pathog. 10, e1003934 (2014).

15. Lee, L.Y. \& Ison, M.G. Diarrhea caused by viruses in transplant recipients. Transpl. Infect. Dis. 16, 347-358 (2014).

16. Ramig, R.F. Pathogenesis of intestinal and systemic rotavirus infection. J. Virol. 78, 10213-10220 (2004).

17. Blutt, S.E., Miller, A.D., Salmon, S.L., Metzger, D.W. \& Conner, M.E. IgA is important for clearance and critical for protection from rotavirus infection. Mucosal Immunol. 5, 712-719 (2012).

18. Franco, M.A. \& Greenberg, H.B. Role of B cells and cytotoxic T lymphocytes in clearance of and immunity to rotavirus infection in mice. J. Virol. 69, 7800-7806 (1995).

19. Deal, E.M., Lahl, K., Narváez, C.F., Butcher, E.C. \& Greenberg, H.B. Plasmacytoid dendritic cells promote rotavirus-induced human and murine B cell responses. J. Clin. Invest. 123, 2464-2474 (2013).

20. Lopatin, U., Blutt, S.E., Conner, M.E. \& Kelsall, B.L. Lymphotoxin alphadeficient mice clear persistent rotavirus infection after local generation of mucosal IgA. J. Virol. 87, 524-530 (2013).

21. Lopez-Guerrero, D.V. et al. Rotavirus infection activates dendritic cells from Peyer's patches in adult mice. J. Virol. 84, 1856-1866 (2010).

22. Pott, J. et al. Age-dependent TLR3 expression of the intestinal epithelium contributes to rotavirus susceptibility. PLoS Pathog. 8, e1002670 (2012).

23. Hernández, P.P. et al. Interferon- $\lambda$ and interleukin 22 act synergistically for the induction of interferon-stimulated genes and control of rotavirus infection. Nat. Immunol. 16, 698-707 (2015).

24. Meredith, M.M. et al. Expression of the zinc finger transcription factor zDC (Zbtb46, Btbd4) defines the classical dendritic cell lineage. J. Exp. Med. 209, 1153-1165 (2012).

25. Cerovic, V. et al. Lymph-borne CD $8 \alpha+$ dendritic cells are uniquely able to cross-prime CD8 + T cells with antigen acquired from intestinal epithelial cells. Mucosal Immunol. 8, 38-48 (2015).

26. Jaimes, M.C., Feng, N. \& Greenberg, H.B. Characterization of homologous and heterologous rotavirus-specific T-cell responses in infant and adult mice. J. Virol. 79, 4568-4579 (2005).

27. Angel, J., Franco, M.A. \& Greenberg, H.B. Rotavirus vaccines: recent developments and future considerations. Nat. Rev. Microbiol. 5, 529-539 (2007).

28. Hirota, K. et al. Plasticity of Th17 cells in Peyer's patches is responsible for the induction of T cell-dependent IgA responses. Nat. Immunol. 14, 372 379 (2013).

29. Welty, N.E. et al. Intestinal lamina propria dendritic cells maintain T cell homeostasis but do not affect commensalism. J. Exp. Med. 210, 20112024 (2013).

30. Meredith, M.M. et al. Zinc finger transcription factor ZDC is a negative regulator required to prevent activation of classical dendritic cells in the steady state. J. Exp. Med. 209, 1583-1593 (2012).

31. Tittel, A.P. et al. Functionally relevant neutrophilia in CD11c diphtheria toxin receptor transgenic mice. Nat. Methods 9, 385-390 (2012).

32. Tussiwand, R. et al. Compensatory dendritic cell development mediated by BATF-IRF interactions. Nature 490, 502-507 (2012).

33. Mayer, L. Epithelial cell antigen presentation. Curr. Opin. Gastroenterol. 16, 531-535 (2000).

34. Adkins, B. \& Du, R.Q. Newborn mice develop balanced Th1/Th2 primary effector responses in vivo but are biased to Th2 secondary responses. J. Immunol. 160, 4217-4224 (1998).

35. Willems, F., Vollstedt, S. \& Suter, M. Phenotype and function of neonatal DC. Eur. J. Immunol. 39, 26-35 (2009).

36. Sheridan, J.F., Smith, C.C., Manak, M.M. \& Aurelian, L. Prevention of rotavirus-induced diarrhea in neonatal mice born to dams immunized with empty capsids of simian rotavirus SA-11. J. Infect. Dis. 149, 434-438 (1984).

37. Muzaki, A.R. et al. Intestinal CD103(+)CD11b(-) dendritic cells restrain colitis via IFN- $\gamma$-induced anti-inflammatory response in epithelial cells. Mucosal Immunol. 9, 336-351 (2016). 


\section{ARTICLES}

38. Luda, K.M. et al. IRF8 transcription-factor-dependent classical dendritic cells are essential for intestinal T cell homeostasis. Immunity 44, 860-874 (2016).

39. Aychek, T. et al. IL-23-mediated mononuclear phagocyte crosstalk protects mice from Citrobacter rodentium-induced colon immunopathology. Nat. Commun. 6, 6525 (2015).

40. Glass, R.I. et al. Rotavirus vaccines: current prospects and future challenges. Lancet 368, 323-332 (2006).
41. Burns, J.W. et al. Analyses of homologous rotavirus infection in the mouse model. Virology 207, 143-153 (1995).

42. Sun, T., Rojas, O.L., Li, C., Philpott, D.J. \& Gommerman, J.L. Hematopoietic LT $\beta$ R deficiency results in skewed T cell cytokine profiles during a mucosal viral infection. J. Leukoc. Biol. 100, 103-110 (2016).

43. Gonzalez, A.M. et al. Rotavirus-specific B cells induced by recent infection in adults and children predominantly express the intestinal homing receptor alpha4beta7. Virology 305, 93-105 (2003). 